\title{
N-Methyl-D-Aspartate Receptor Hypofunction in Meg-01 Cells Reveals a Role for Intracellular Calcium Homeostasis in Balancing Megakaryocytic-Erythroid Differentiation
}

\author{
Stefan K. Bohlander ${ }^{1}$ Maggie L. Kalev-Zylinska ${ }^{1,5}$

\footnotetext{
${ }^{1}$ Department of Molecular Medicine and Pathology, School of Medical Sciences, University of Auckland, Auckland, New Zealand

${ }^{2}$ Department of Medicine, School of Medicine, University of Auckland, Auckland, New Zealand

3 Department of Pharmacology and Clinical Pharmacology, School of Medical Sciences, University of Auckland, Auckland, New Zealand

${ }^{4}$ Auckland Cancer Society Research Centre, University of Auckland, Auckland, New Zealand

${ }^{5}$ LabPlus Haematology, Auckland City Hospital, Auckland, New Zealand
}

James I. Hearn ${ }^{1}$ Taryn N. Green ${ }^{1}$ Martin Chopra ${ }^{1}$ Yohanes N. S. Nursalim ${ }^{1}$ Leandro Ladvanszky ${ }^{1}$ Nicholas Knowlton ${ }^{1}$ Cherie Blenkiron ${ }^{1}$ Raewyn C. Poulsen ${ }^{2,3}$ Dean C. Singleton ${ }^{4}$

Address for correspondence Maggie L. Kalev-Zylinska, MD, PhD, FRCPA, Department of Molecular Medicine and Pathology, University of Auckland, 85 Park Road, Grafton, Private Bag 92019, Auckland, New Zealand (e-mail: m.kalev@auckland.ac.nz).

\author{
Abstract \\ Keywords \\ - N-methyl-D-aspartate \\ receptor \\ - endoplasmic \\ reticulum stress \\ - intracellular calcium \\ - megakaryocyte \\ - erythropoiesis
}

The release of calcium ions $\left(\mathrm{Ca}^{2+}\right)$ from the endoplasmic reticulum (ER) and related storeoperated calcium entry (SOCE) regulate maturation of normal megakaryocytes. The $\mathrm{N}$ methyl-D-aspartate (NMDA) receptor (NMDAR) provides an additional mechanism for $\mathrm{Ca}^{2+}$ influx in megakaryocytic cells, but its role remains unclear. We created a model of NMDAR hypofunction in Meg-01 cells using CRISPR-Cas9 mediated knockout of the GRIN1 gene, which encodes an obligate, GluN1 subunit of the NMDAR. We found that compared with unmodified Meg-01 cells, Meg-01-GRIN1 ${ }^{-1-}$ cells underwent atypical differentiation biased toward erythropoiesis, associated with increased basal ER stress and cell death. Resting cytoplasmic $\mathrm{Ca}^{2+}$ levels were higher in Meg-01-GRIN1 ${ }^{-1-}$ cells, but ER $\mathrm{Ca}^{2+}$ release and SOCE were lower after activation. Lysosome-related organelles accumulated including immature dense granules that may have contributed an alternative source of intracellular $\mathrm{Ca}^{2+}$. Microarray analysis revealed that Meg-01-GRIN1 ${ }^{-1-}$ cells had deregulated expression of transcripts involved in $\mathrm{Ca}^{2+}$ metabolism, together with a shift in the pattern of hematopoietic transcription factors toward erythropoiesis. In keeping with the observed pro-cell death phenotype induced by GRIN1 deletion, memantine (NMDAR inhibitor) increased cytotoxic effects of cytarabine in unmodified Meg-01 cells. In conclusion, NMDARs comprise an integral component of the $\mathrm{Ca}^{2+}$ regulatory network in Meg-01 cells that help balance ER stress and megakaryocytic-erythroid differentiation. We also provide the first evidence that megakaryocytic NMDARs regulate biogenesis of lysosome-related organelles, including dense granules. Our results argue that intracellular $\mathrm{Ca}^{2+}$ homeostasis may be more important for normal megakaryocytic and erythroid differentiation than currently recognized; thus, modulation may offer therapeutic opportunities. received

September 21, 2019

accepted

February 4, 2020
DOI https://doi.org/

$10.1055 / \mathrm{s}-0040-1708483$

ISSN 0340-6245. (c) 2020 Georg Thieme Verlag KG Stuttgart · New York
License terms

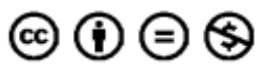




\section{Introduction}

Calcium $\left(\mathrm{Ca}^{2+}\right)$ is an ubiquitous but versatile cytosolic second messenger, oscillations of which regulate gene transcription, including in megakaryocytes (MKs). ${ }^{1,2}$ Resting cells maintain cytosolic $\mathrm{Ca}^{2+}$ concentrations at very low levels to inhibit apoptosis. This is achieved through the transport of cytosolic $\mathrm{Ca}^{2+}$ into the extracellular space or sequestration of $\mathrm{Ca}^{2+}$ into intracellular stores, of which endoplasmic reticulum (ER) is the main site. Molecules that maintain intracellular $\mathrm{Ca}^{2+}$ homeostasis include diverse $\mathrm{Ca}^{2+}$ channels, pumps, exchangers and binding proteins, collectively known as the $\mathrm{Ca}^{2+}$ signaling "toolkit." On the background of normal $\mathrm{Ca}^{2+}$ homeostasis, oscillations in cytosolic $\mathrm{Ca}^{2+}$ levels that vary in amplitude, frequency and duration translate into specific cellular effects. ${ }^{1}$

The principles of intracellular $\mathrm{Ca}^{2+}$ homeostasis in MKs are similar to those in other cells. MK surface receptors activate phospholipase C (PLC) that generates inositol 1,4,5-trisphosphate (IP3)., ${ }^{2,3}$ IP3 binds to IP3 receptors (IP3Rs) located on the ER membrane, triggering the release of $\mathrm{Ca}^{2+}$ from the ER. Depleted $\mathrm{ERCa}^{2+}$ stores are refilled from the extracellular space through the process called storeoperated calcium entry (SOCE), facilitated by stromal interaction molecule 1 (STIM1). STIM1 recruits ORAI1 channels in the plasma membrane that refill ER $\mathrm{Ca}^{2+}$ stores. High levels of cytosolic $\mathrm{Ca}^{2+}$ that arise during cell activation are normalized by two main types of $\mathrm{Ca}^{2+}$ pumps that either transport $\mathrm{Ca}^{2+}$ back to the extracellular space (plasma membrane $\mathrm{Ca}^{2+}$ ATPases [PMCA]) or to the ER (sarco-/endo-plasmic reticulum $\mathrm{Ca}^{2+}$ ATPases [SERCA]). ${ }^{4}$

Both $\mathrm{ER} \mathrm{Ca}^{2+}$ release and SOCE are known to regulate MK development and maturation. In megakaryocytic progenitors, sustained SOCE activates the calcineurin-nuclear factor of activated T cells (NFAT) pathway that inhibits cell proliferation. ${ }^{5}$ In mature MKs, SOCE supports MK migration, and $\mathrm{ER} \mathrm{Ca}^{2+}$ release triggers MK adhesion and proplatelet formation. ${ }^{6}$ SOCE represents the main pathway for $\mathrm{Ca}^{2+}$ entry in most cells, but MKs also express other $\mathrm{Ca}^{2+}$ channels located in the plasma membrane, including transient receptor potential cation (TRPC) and $N$-methyl-D-aspartate (NMDA) receptors (NMDARs), the roles of which are much less understood.

NMDARs are glutamate gated, nonspecific cation channels with high $\mathrm{Ca}^{2+}$ permeability. ${ }^{7}$ The first evidence that NMDARs operate as ion channels in MKs was obtained by Genever et al, who demonstrated that tritiated MK-801 injected into mice intracardially bound to MKs in the bone marrow examined 15 minutes later. ${ }^{8}$ Because MK-801 can only bind within an open NMDAR pore, ${ }^{9}$ its labeling of MKs was consistent with the NMDAR function as ion channel in these cells. Later, we showed that glutamate, NMDA and glycine induce $\mathrm{Ca}^{2+}$ fluxes in Meg-01 cells, and NMDAR blockers (memantine and MK-801) counteract this effect. $^{10,11}$ Others and we also found that memantine and MK-801 inhibit differentiation of normal mouse and human MKs ex vivo but induce differentiation of leukemic Meg-01 cells in vitro. ${ }^{8,10-12}$ Further characterization of NMDAR effects using chemical modulators was restricted by toxic, likely off-target effects. Thus, we undertook a gene knockout approach in Meg-01 cells.

We hypothesized that NMDAR-mediated $\mathrm{Ca}^{2+}$ influx contributes to intracellular $\mathrm{Ca}^{2+}$ homeostasis in megakaryocytic cells, which impacts the transcriptional program of cell differentiation. Using CRISPR-Cas9, we attenuated NMDAR function in a Meg-01 cell line as a model of megakaryocyticerythroid progenitors and examined subsequent effects on cell phenotype. Our results suggest an important role of intracellular $\mathrm{Ca}^{2+}$ homeostasis in balancing megakaryocyticerythroid differentiation.

\section{Methods}

\section{Cell Culture}

Meg-01 cells (German Collection of Microorganisms and Cell Cultures, Braunschweig, Germany) were used as models of human megakaryocytic-erythroid progenitors. Meg-01 cell line is derived from acute megakaryoblastic leukemia transformed from chronic myeloid leukemia, but cells undergo megakaryocytic differentiation. ${ }^{13-15}$ Meg01 and Meg-01-GRIN1 ${ }^{-1-}$ cells were maintained at $37^{\circ} \mathrm{C}$, $5 \% \mathrm{CO}_{2}$, in RPMI- 1640 medium supplemented with $2 \mathrm{mM}$ L-glutamine and $10 \%$ foetal bovine serum (FBS; all from Thermo Fisher Scientific, Waltham, Massachusetts, United States), as described previously. ${ }^{10}$ To induce differentiation, cells were cultured in the presence of phorbol-12myristate-13-acetate (10 nM; PMA; Sigma-Aldrich, Saint Louis, Missouri, United States) for 72 hours. TrypLE (Thermo Fisher Scientific) was used to collect adherent cells for analysis. Cultures were confirmed to be free from mycoplasma infection using LookOut Mycoplasma PCR Detection Kit (Sigma-Aldrich).

\section{CRISPR-Cas9 Plasmid Design and Transfection}

The CRISPR-Cas9 system was applied using a single guide RNA (gRNA) to induce an insertion/deletion (INDEL) causing a frameshift in the GRIN1 gene. The genomic target sequence was positioned in exon 1 of GRIN1, downstream of all known start codons for the gene. The sequence 5'-CAAGATCGTCAACATTGGCG-3' was cloned into a modified pMIG plasmid containing an orange fluorescent protein (OFP) reporter sequence (pMIG-Alpha was a gift from William Hahn, Addgene plasmid \#9044; http://n2t.net/addgene:9044 RRID: Addgene_9044; Addgene, Watertown, Massachusetts, United States). ${ }^{16}$ Meg-01 cells were transfected with an endotoxin free preparation of the plasmid using Lipofectamine 3000 (Thermo Fisher Scientific). After 48 hours, single, high OFP expressing cells were sorted into 96-well plates using the FACSAria II (Becton Dickson, Franknlin Lakes, New Jersey, United States). Cells were cultured in RPMI-1640 supplemented with 2 mM Glutamax, 25 mM HEPES (4-[2-hydroxyethyl]-1-piperazineethanesulfonic acid), $1 \mathrm{mM}$ sodium pyruvate and $40 \%$ FBS for 2 weeks. The DNA from the clones was amplified using primers (forward: 5 '-CTCCGACACACACGCTCAC-3', reverse: 5'-ATAGGCGAGCCAGCAGACC-3') targeting the gRNA target site, and amplicons were screened for INDELs by Sanger sequencing. 


\section{Transfection of Short Interfering RNA}

Meg- 01 cells were plated at $6 \times 10^{5}$ cells per well in a six-well plate and allowed to adhere for 4 hours. Endoribonucleaseprepared short interfering RNA (esiRNA) targeting GRIN1 (esiGRIN1; EHU157091, Sigma-Aldrich) were used to transiently knockdown GRIN1 in Meg-01 cells. Transfections were done in serum-free OptiMEM media assisted by Lipofectamine RNAimax (both from Thermo Fisher Scientific). OptiMEM was replaced with complete culture media 12 hours after transfections, and cells were harvested for analysis 60 hours later. ${ }^{17}$

\section{[ $\left.{ }^{3} \mathrm{H}\right] \mathrm{MK}-801$ Binding Assay}

$\left[{ }^{3} \mathrm{H}\right] \mathrm{MK}-801$ was used to label open (i.e. active) NMDARs. Cells were plated at $5 \times 10^{5}$ cells per well in 24-well plates and allowed to adhere for 4 hours. $\left[{ }^{3} \mathrm{H}\right] \mathrm{MK}-801(5 \mathrm{nM}, 1 \mu \mathrm{Ci}$ $\mathrm{L}^{-1}$ ) (Perkin Elmer, Waltham, Massachusetts, United States) and glutamate $500 \mu \mathrm{M}$ (NMDAR agonist; Sigma-Aldrich) were added and incubated with cells for 1 hour. Media was removed, cells were washed with serum-free media, and solubilized with $1 \mathrm{~N} \mathrm{NaOH}$. $\beta$-particle emission was recorded as counts per second using a Wallac Microbeta 1450-021 TriLux Luminometer Liquid Scintillation Counter (LabEquip, Markham, Canada) as described previously. ${ }^{17}$

\section{Cell Viability, Proliferation and Cell Death Assays}

Cell viability and proliferation assays were done as previously described. ${ }^{11}$ Briefly, cells were seeded at $1 \times 10^{4}$ cells per well in 96-well plates and cultured for 72 hours prior to testing using an MTT kit (Thermo Fisher Scientific). Cell proliferation was examined using the Cell Proliferation ELISA BrdU kit (Roche, Basel, Switzerland) after incubation with bromodeoxyuridine (BrdU) for 6 hours. Cytotoxicity was measured using the Cytotoxicity Detection KitPLUS (lactate dehydrogenase [LDH] release assay; Roche). Selected cell survival assays used the following chemicals: NMDA (synthetic NMDAR agonist, $100 \mu \mathrm{M}$ ), L-glutamate (main NMDAR agonist, $500 \mu \mathrm{M}$; both from Sigma-Aldrich), glycine (NMDAR co-agonist, $300 \mu \mathrm{M}$; VWR International, Radnor, Pennsylvania, United States), memantine (NMDAR antagonist, $100 \mu \mathrm{M}$; Sigma-Aldrich), and cytarabine $(0.1 \mu \mathrm{M}$; Cayman Chemical, Ann Arbor, Michigan, United States).

\section{Recordings of Intracellular Calcium Responses}

Intracellular $\mathrm{Ca}^{2+}$ responses were monitored using the Fura-2 Calcium Assay Kit (Abcam, Cambridge, United Kingdom). Cells were plated in poly-D-lysine (Sigma-Aldrich) treated glassbottom, black, 96 -well plates at $9 \times 10^{4}$ cells per well. Cells were allowed to adhere for 4 hours, then washed with $1 \times$ Hank's Balanced Salt Solution (HBSS), and loaded with Fura-2$\mathrm{Am}$ at $37^{\circ} \mathrm{C}$ for 1 hour in the dark. Fluorescence was measured using a $510 \mathrm{~nm}$ emission filter with 340 and $380 \mathrm{~nm}$ excitation filters from the bottom of the plate with a Tecan Spark Multiplate Reader (Tecan, Männedorf, Switzerland) at $37^{\circ} \mathrm{C}, 5 \% \mathrm{CO}_{2}$. Signals were acquired every second for 30 seconds to establish a baseline and then again every second for a further 120 seconds after the addition of NMDA $(100 \mu \mathrm{M})$ with glycine $(300 \mu \mathrm{M})$ or glutamate $(500 \mu \mathrm{M})$ with glycine $(300 \mu \mathrm{M})$, both with or without BAPTA ( $5 \mathrm{mM}$; 1,2-bis(o-aminophenoxy)ethane-N,N,N',N'-tetraacetic acid, cell-impermeant calcium chelator; Thermo Fisher Scientific). Other experiments used thapsigargin $(2 \mu \mathrm{M})$ and ionomycin $\left(5 \mu \mathrm{g} \mathrm{mL}^{-1}\right.$; both from Sigma-Aldrich).

To measure SOCE fluxes, cells were seeded at $2 \times 10^{4}$ cells per well and cultured for 3 days. Cells were washed with $1 \times$ physiological saline prior to loading with Fura-2-Am as above. $\mathrm{Ca}^{2+}$ signals were measured every 30 seconds for 5 minutes to establish a baseline. Media was then changed to $\mathrm{Ca}^{2+}$ and $\mathrm{Mg}^{2+}$ free physiological saline, supplemented with cyclopiazonic acid $\left(10 \mu \mathrm{M}\right.$; a SERCA inhibitor that depletes ER $\mathrm{Ca}^{2+}$ stores) and EGTA ( $500 \mu \mathrm{M}$; ethylene glycol-bis( $\beta$-aminoethyl ether)-N,N,N',N'-tetraacetic acid, a cell-impermeant calcium chelator; both from Sigma-Aldrich), and signals were recorded every 30 seconds for 7.5 minutes. Media was then changed to physiological saline, and monitoring continued every 30 seconds for a further 12.5 minutes. Fluorescence was measured using a $510 \mathrm{~nm}$ emission filter with 340 and $380 \mathrm{~nm}$ excitation filters as above. Relative intracellular $\mathrm{Ca}^{2+}$ levels were determined, based on the measurement of a fluorescent $340 / 380 \mathrm{~nm}$ ratio.

\section{Flow Cytometry}

Nuclear ploidy analysis was performed by staining cells (0.5$1 \times 10^{5}$ per tube) with propidium iodide $50 \mu \mathrm{g} \mathrm{mL}^{-1}$ in a hypotonic sodium citrate buffer $(0.1 \%)$ for 35 minutes on ice. Cells were washed, resuspended in RPMI-1640, and treated with RNAse $50 \mu \mathrm{g} \mathrm{mL}^{-1}$ at room temperature (RT) for 30 minutes.

The following antibodies (catolog number) were used to characterize myeloid antigen expression: CD13 (561698), CD33 (561816), CD41 (555466), CD42a (558819), CD42b (555473), CD61 (555754), CD71 (347513) (all from BD Biosciences, San Jose, California, United States) and CD235a (IM2212; from Beckman Coulter, Bea, California, United States). Cells $\left(0.5-1 \times 10^{5}\right)$ were incubated with the antibodies for 15 minutes at RT, washed with wash buffer $(1 \times$ phosphate buffered saline [PBS], 2\% FBS, $0.02 \%$ sodium azide), and fixed with $0.5 \%$ paraformaldehyde (PFA) in $1 \times$ PBS.

ER-Tracker Red $(10 \mu \mathrm{M})$ and LysoTracker Red DNA-99 $(50 \mathrm{nM})$ (both from Thermo Fisher Scientific) were incubated with cells $\left(0.5-1 \times 10^{5}\right)$ at $37^{\circ} \mathrm{C}, 5 \% \mathrm{CO}_{2}$ for 45 and 60 minutes, respectively. Cells were washed with wash buffer and fixed with $0.5 \%$ PFA in $1 \times$ PBS. All flow cytometry data were acquired on the BD LSRII flow cytometer and analyzed using BD FACSDiVa software v6.1.1.

\section{Microscopy Examination and Ultrastructure}

For immunofluorescence, cells were fixed in 4\% PFA in $1 \times$ PBS for 15 to 20 minutes and permeabilized for 5 minutes with $0.1 \%$ Triton X-100 in PBS. Cells were blocked for 30 minutes with 5\% goat serum and then incubated with primary antibodies (CD63 1:200, ab59479, Abcam; GluN1 1:500, MAB363, Merk \& Co, Kenilworth, New Jersey, United States or Calnexin 1:1000, ab22595, Abcam) at $4^{\circ} \mathrm{C}$ overnight. After washing, cells were incubated with $2.5 \mu \mathrm{g} \mathrm{mL} \mathrm{m}^{-1}$ Dylight 488/594-conjugated secondary antibodies (ab96931 and ab96885, respectively; both from Abcam) for 3 hours. Giemsa staining was performed 
using the Cytopro autostainer (ELITech, Paris, France). Brightfield and immunofluorescence microscopy was conducted using an Eclipse Ni-E microscope (Nikon, Tokyo, Japan). Hoffman and phase contrast images were taken on an Eclipse Ti microscope (Nikon).

Transmission electron microscopy was done as previously described. ${ }^{18}$ Briefly, cells were fixed with $0.2 \%$ glutaraldehyde and 2\% PFA in White's saline. Sections were counterstained with uranyl acetate and examined with a Tecnai G2 Spirit Twin transmission electron microscope (FEI Company, Hillsboro, Oregon, United States).

\section{Western Blotting}

Cells were lysed in radio-immunoprecipitation assay buffer (50 mM Tris pH 4.7, 150 mM NaCl, 1\% NP-40, 0.25\% Na-deoxycholate, and $1 \mathrm{mM}$ EDTA) with protease and phosphatase inhibitors (Sigma-Aldrich). Cell lysates were quantified using the Pierce BCA protein asay kit (Thermo Fisher Scientific), and proteins were resolved on a 4 to $15 \%$ SDS-PAGE gradient gel. Separated proteins were electrophoretically transferred onto polyvinylidene difluoride membranes for subsequent probing with antibodies (CD63 1:1000, ab59479, Abcam; LC3-II 1:1000, CTE4108S, Thermo Fisher Scientific; pan-Actin 1:10000, MAB1501, Abcam). Membranes were washed and incubated with horseradish peroxidase conjugated secondary antibodies (111-035-003, Jackson ImmunoResearch, Pennyslvania, United States). Clarity Western ECL (Bio-Rad, Hercules, California, United States) was used for signal detection using Chemidoc Touch (Bio-Rad). Membranes were stained with Coomassie Blue to observe total protein. Relative protein quantitation was performed by band densitometry using ImageLab 5.2.1 (BioRad); LC3-II was quantified relative to actin, and CD63 relative to total protein after Coomassie staining.

\section{RNA Isolation, complementary DNA Synthesis, and Reverse Transcriptase-Polymerase Chain Reaction}

Total RNAwas isolated from cells using TRIzol and the PureLink RNA Mini Kit (both from Thermo Fisher Scientific) following the manufacturer's instructions. On-column DNase digestion was performed using the Purelink DNase set (Thermo Fisher Scientific). Complementary DNA (cDNA) was synthesized using the Quanta qScript XLT cDNA SuperMix (Quantabio, Beverley, Massachusetts, United States). Reverse Transcriptase-quantitative Polymerase Chain Reaction (RT-qPCR) was performed in $10 \mu \mathrm{L}$ reactions using SYBR Select Master Mix (Thermo Fisher Scientific) for ER stress expression and Perfecta SYBR Green FastMix (Quantabio) for GRIN1 expression and microarray validation, run on the QuantStudio $12 \mathrm{~K}$ Flex RealTime PCR instrument (Thermo Fisher Scientific). Relative expression levels of each gene were normalized to $L M N A$, HPRT1 and GAPDH housekeeping genes, chosen as they remained invariant in our RNA microarray analysis. Relative changes to unmodified Meg-01 cells were calculated using the $2^{-\Delta \Delta \mathrm{Ct}}$ method. ${ }^{19}$ At least three biological replicates were included for each condition in each experiment. Primer sequences used for the genes encoding ER stress markers, ${ }^{20}$ NMDAR subunits, ${ }^{18}$ LMNA, $^{21}$ and HPRT $1{ }^{22}$ were as previously published. Microarray validation was performed using Prime-
Time qPCR primer assays from Integrated DNA Technologies (Coralville, Iowa, United States); all primer details are in -Supplementary Table S1 (available in the online version).

\section{Gene Expression Profiling and Gene Ontology Analysis} RNA was isolated as described above. Gene expression profiling was performed using the Clariom $S$ microarray assay (Thermo Fisher Scientific). Data were normalized by gene level Robust Multi-array Average method. ${ }^{23}$ Unmodified Meg-01 and Meg-01-GRIN1 ${ }^{-/-}$cells were assayed in triplicate. Differentially expressed (DE) genes were identified using eBays one-way analysis of variance (ANOVA) with a Benjamini-Hochberg false discovery rate (FDR) of 0.05; analysis was done using Transcriptome Analysis Console 4.0 (Thermo Fisher Scientific).

The overrepresentation enrichment analysis was performed on DE genes with a high fold change $(\geq 2.0)$ to identify whether any gene ontology (GO) defined biological processes occurred more than chance would dictate. The GO-Slim set-up was selected to reduce the overlap between the GO processes. The over-representation analysis was performed using the PANTHER V14.1 online tool (http://pantherdb.org; accessed May 2019). A more relaxed cutoff (fold change $\geq 1.5 ; \mathrm{FDR} \leq 0.05$ ) was applied to interrogate expression of genes within the deregulated biological processes, in particular genes coding for the $\mathrm{Ca}^{2+}$ toolkit and hematopoietic transcription factors. Statistical enrichment was determined via Fischer's exact test; a conservative Bonferroni correction was applied to all nominal $p$-values.

\section{Statistical Analysis}

Data are expressed as mean \pm standard error of the mean (SEM). Statistical analyses were conducted using GraphPad Prism 8.0 (San Diego, California, United States). Differences in group means were compared with either a Student's $t$-test (two-tailed) or one-way ANOVA with Dunnett post hoc for continuous variables, as indicated in figure legends. An $\alpha$ of 0.05 was considered statistically significant.

\section{Results}

\section{Generating a Model of Reduced NMDAR Expression in Megakaryocytic Cells}

Using CRISPR-Cas9, we knocked out the expression of the GRIN1 gene in Meg-01 cells; GRIN1 encodes an obligate, GluN1 subunit of the NMDAR. A pMIG plasmid was modified to carry gRNA targeting exon 1 of GRIN1. Forty-eight hours after transfection, Meg-01 cells showing high expression of the OFP reporter were sorted by flow cytometry and grown into single cell colonies. Candidate cell clones were screened by Sanger sequencing of the modified genetic region. A clone was identified with a 59 bp deletion in both GRIN1 alleles, predicted to cause a frame-shift and premature stop codons in exons 2 and 3 of GRIN1 (Meg-01-GRIN1 ${ }^{-/}$cells; -Fig. 1A).

Examination by RT-qPCR demonstrated a $91 \pm 3 \%$ knockdown of GRIN1 mRNA compared with unmodified Meg-01 cells (- Fig. 1Bi). Binding of $\left[{ }^{3} \mathrm{H}\right] \mathrm{MK}-801$, use-dependent NMDAR antagonist, was reduced by $72 \pm 16 \%$, indicating low numbers of remaining functional NMDARs (-Fig. 1Bii). 
A

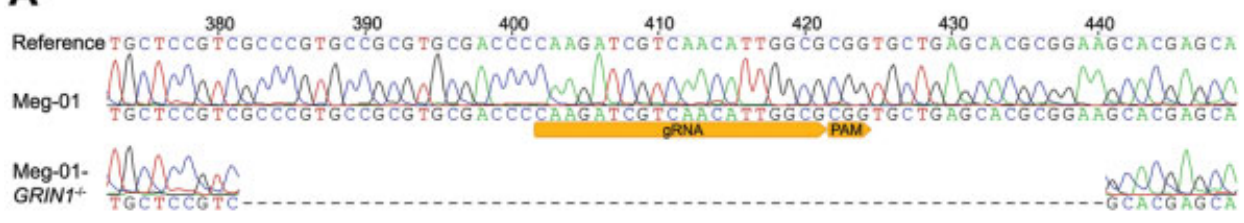

B
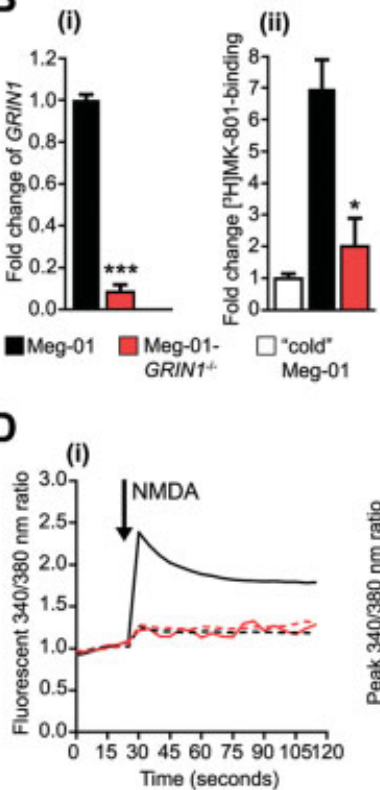

E

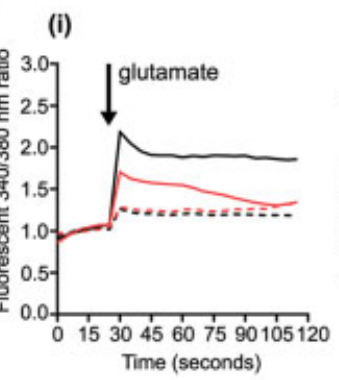

C

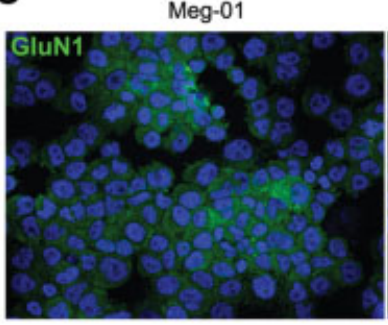

Meg-01-GRIN1+

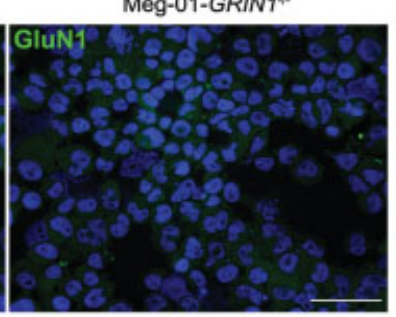

(ii)

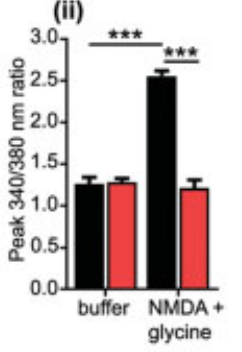

(ii)

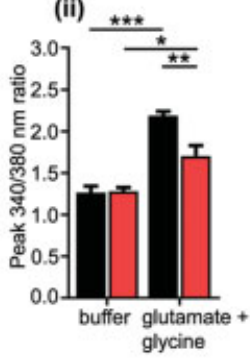

(iii)

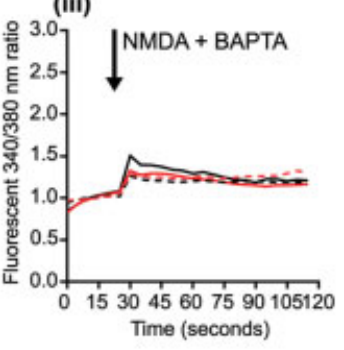

(iii)

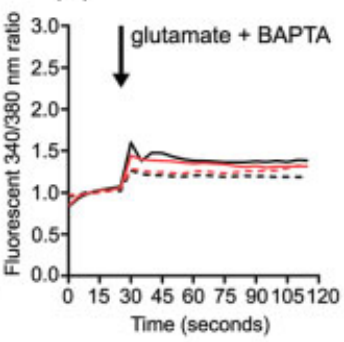

(iv)

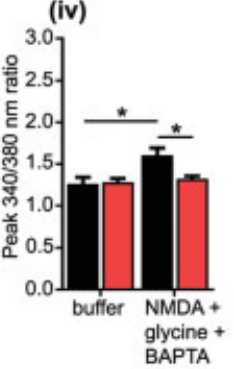

(iv)

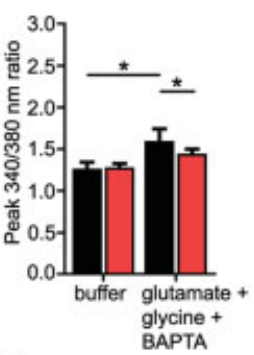

-.- Meg-01: buffer

- Meg-01: agonist -1+ BAPTA

-*- Meg-01-GRIN1+: buffer - Meg-01-GRIN1+3 agonist -1+ BAPTA

- Meg-01

Meg-01-GRIN1+

Fig. 1 Validation of the GRIN1 knockout in Meg-01 cells (Meg-01-GRIN1 ${ }^{-/-}$cells). (A) Sequence alignment of Sanger sequences obtained from unmodified Meg-01 cells and Meg-01-GRIN1 ${ }^{-/-}$cells to the GRIN1 reference sequence (National Center for Biotechnology Information accession number NG_011507.1) for nucleotides 373-449 (exon 1). The dashed line indicates the region of gene deletion ( $59 \mathrm{bP}$ ) generated by CRISPR-Cas9. The relative positions of the guide RNA (gRNA) target and protospacer adjacent motif (PAM) sequences are shown (yellow arrows). (B) Bar graphs showing relative levels of GRIN1 mRNA expression examined by RT-qPCR (i) and [ $\left.{ }^{3} \mathrm{H}\right] \mathrm{MK}-801$ binding (ii) in Meg-01-GRIN1 ${ }^{-/}$cells, calculated relative to unmodified Meg-01 cells. Bars are mean \pm standard error of the mean from four independent experiments for RT-qPCR and two for [ $\left.{ }^{3} \mathrm{H}\right] \mathrm{MK}-801$ binding, each in triplicate. "Cold" Meg-01 indicates [ $\left.{ }^{3} \mathrm{H}\right] \mathrm{MK}-801$ binding by Meg-01 cells after incubation with nonradioactive ("cold") MK-801 (specificity control). (C) Representative images showing GluN1 immunofluorescence staining in Meg-01 and Meg-01-GRIN1 ${ }^{-/-}$cells. Scale bar, $50 \mu M$ for both. (D, E) NMDAR-mediated intracellular calcium responses were measured relative to baseline set at (1.0) in Meg-01 and Meg-01-GRIN1-/- cells. Cells were loaded with Fura-2-AM and stimulated with NMDAR agonists in the presence of extracellular $\mathrm{Ca}^{2+}$ : NMDA $100 \mu \mathrm{M}$ without and with BAPTA $10 \mathrm{mM} \mathrm{D}$ (i, ii, iii and iv, respectively); and glutamate $500 \mu \mathrm{M}$ without and with BAPTA $10 \mathrm{mM} \mathrm{E}$ (i, ii, iii and iv, respectively). Line graphs in D and E show the mean fluorescent $340 / 380 \mathrm{~nm}$ ratio of Fura-2 recorded over 120 seconds corresponding bar graphs show the peak level (mean \pm standard error of the mean) of the fluorescent $340 / 380 \mathrm{~nm}$ ratio recorded during the observation period. Buffer indicates control. Each experimental condition was repeated five times, in triplicate. Statistical significance is shown (Student's $t$-test for B and one-way ANOVA with Dunnett post hoc for D and E; $\left.{ }^{*} p<0.05,{ }^{* *} p<0.01,{ }^{* * *} p<0.001\right)$. BAPTA, 1,2-bis(o-aminophenoxy) ethane-N,N,N,Ntetraacetic acid; gRNA, guide RNA; NMDAR, $N$-methyl-D-aspartate receptor; PAM, protospacer adjacent motif; RT-qPCR, quantitative reverse transcriptasepolymerase chain reaction. 
Immunofluorescence demonstrated minimal staining for the GluN1 protein (-Fig. 1C). The virtual loss of $\mathrm{Ca}^{2+}$ influx through NMDAR was confirmed by the examination of $\mathrm{Ca}^{2+}$ fluxes in

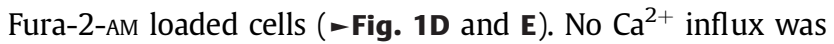
recorded in Meg-01-GRIN1 ${ }^{-/-}$cells in response to $100 \mu \mathrm{M}$ NMDA (synthetic but specific NMDAR agonist; - Fig. 1Di-ii). Peak $\mathrm{Ca}^{2+}$ responses to $500 \mu \mathrm{M}$ glutamate (endogenous but nonspecific NMDAR agonist) were 54\% lower in Meg-01GRIN1 $^{-/}$cells compared with unmodified Meg-01 cells (-Fig. 1Ei-ii), implying contribution from other glutamate receptors. The effect of GRIN1 deletion on NMDAR-evoked $\mathrm{Ca}^{2+}$ influx resembled that of memantine (NMDAR blocker), supporting that Meg-01-GRIN1 ${ }^{-/}$cells provided a valid model of reduced NMDAR-mediated $\mathrm{Ca}^{2+}$ entry in Meg-01 cells (-Supplementary Fig. S1, available in the online version).

\section{Loss of $\mathbf{N}$-Methyl-D-Aspartate Receptor Function Has an Antiproliferative and Proapoptotic Effect}

Morphologically, Meg-01-GRIN1 ${ }^{-/-}$cells were larger, more adherent, and multiplied visibly slower, compared with unmodified Meg-01 cells (-Fig. 2A; - Videos 1 and 2). Congruently, MTT activity and BrdU incorporation were lower, confirming reduced cell numbers and proliferation respectively (-Fig. 2B and C). When culture media was supplemented with NMDA $(100 \mu \mathrm{M})$ or glutamate $(500 \mu \mathrm{M})$, proliferation of unmodified Meg-01 cells increased but not of Meg-01-GRIN1 ${ }^{-/}$

cells ( - Fig. 2C), providing additional evidence that the GRIN1 knockout reduced NMDAR function. LDH release was higher for Meg-01-GRIN1 ${ }^{-/-}$cells during normal culture, implying an increased level of basal cell death ( - Fig. 2D).

\section{Video 1}

Growth pattern of Meg-01 cells in culture over 24-hour period. Time-lapse microscopy was performed using a Nikon TE2000E inverted microscope equipped with an automated stage, a 20X 0.25 numerical aperture Hoffman modulation contrast objective, and a Solent incubation system $\left(37^{\circ} \mathrm{C}, 5 \% \mathrm{CO} 2\right.$; Solent Scientific Limited, Portsmouth, United Kingdom). Cells were grown in RPMI-1640 supplemented with 10\% FBS. Images were acquired every 10 minutes over 24 hours and videos were assembled using NIS-Elements (Nikon). Online content including video sequences viewable at: https://www.thieme-connect.com/products/ejournals/ html/10.1055/s-0040-1708483.

\section{Video 2}

Growth pattern of Meg-01-GRIN1 ${ }^{-1-}$ cells in culture over 24-hour period. Time-lapse microscopy was performed as for - Video 1. Online content including video sequences viewable at: https://www.thieme-connect.com/products/ejournals/html/10.1055/s-0040-1708483.
Flow cytometric measurement of DNA content after staining with propidium iodide showed increased ploidy in Meg-01-GRIN1 ${ }^{-/-}$cells, suggesting megakaryocytic differentiation (-Fig. 2E). However, unexpectedly, expression of megakaryocytic markers (CD41a, CD61; - Fig. 2F and Gi-ii; - Supplementary Fig. S2, available in the online version) and CD42a and CD42b ( - Supplementary Figs \$3 and \$4, available in the online version) were lower. Instead, erythroid markers (CD235a and CD71) were higher, implying increased differentiation toward the erythroid lineage ( - Fig. $\mathbf{2 F}$ and $\mathbf{G i i i - i v ; ~}$ -Supplementary Figs $\mathbf{S 5}$ and $\mathbf{5 6}$, available in the online version).

Other distinctive features of Meg-01-GRIN1 ${ }^{-/-}$cells included progressive accumulation of cytoplasmic vacuoles and granules (-Fig. 3). Some vacuoles were small, located mostly in the perinuclear location (- Fig. $\mathbf{3 A}$ and B; black arrowheads), others were large, distributed throughout the cytoplasm (-Fig. 3A and B; black arrows). Transmission electron microscopy was performed to clarify the cytoplasmic content, which revealed that some cells were filled with vacuolar-like structures, including frequent immature dense granules (-Fig. 3C; blue arrowheads). Staining with CD63 and LysoTracker was increased, confirming accumulation of lysosome-related organelles (- Fig. 4A-C; -Supplementary Fig. S7A and B, available in the online version); in Meg-01 cells these are known to include both lysosomes and developing dense granules. ${ }^{24}$ The lysosomal accumulation raised the possibility of increased autophagy, the induction of which was confirmed by higher lipidation of microtubule associated protein 1 light chain 3 (LC3) compared with unmodified Meg-01 cells (-Fig. 4D; -Supplementary Fig. S8, available in the online version). The ER-Tracker staining was increased in Meg-01-GRIN1 ${ }^{-/-}$ cells when tested by flow cytometry suggesting ER expansion ( - Fig. 4E; - Supplementary Fig. S7C, available in the online version), corroborated by Calnexin immunofluorescence (-Supplementary Fig. S9, available in the online version). The ER expansion suggested ER stress, which was confirmed by RT-qPCR of selected ER stress markers (-Fig. 4F). In contrast to the increased presence of dense granules in Meg-01-GRIN1 ${ }^{-/-}$cells, there was no evidence that $\alpha$-granules accumulated, as expression of P-selectin (CD62P) and von Willebrand factor remained low (-Supplementary Fig. S10, available in the online version).

\section{Intracellular Calcium Homeostasis is Disturbed in Meg-01-GRIN1 ${ }^{-I}$ - Cells}

Intracellular $\mathrm{Ca}^{2+}$ transients were measured in cells loaded with Fura 2-AM (-Fig. 5). We found that compared with unmodified Meg-01 cells, Meg-01-GRIN1 ${ }^{-1-}$ cells had elevated cytosolic $\mathrm{Ca}^{2+}$ levels at baseline ( $\mathbf{F i g . 5 A i}$ and Aii). In contrast, an effect of ER $\mathrm{Ca}^{2+}$ release tested in the presence of cyclopiazonic acid (an inhibitor of SERCA) was reduced ( - Fig. 5Ai and Aiii). Similarly, the SOCE effect, measured after re-addition of extracellular $\mathrm{Ca}^{2+}$, was lower (- Fig. 5Ai and Aiv). Application of thapsigargin (another SERCA inhibitor) and ionomycin $\left(\mathrm{Ca}^{2+}\right.$ ionophore) confirmed reduced contribution of ER $\mathrm{Ca}^{2+}$ in Meg-01-GRIN1 ${ }^{-/}$cells (-Fig. 5B and C, respectively). 


\section{A}

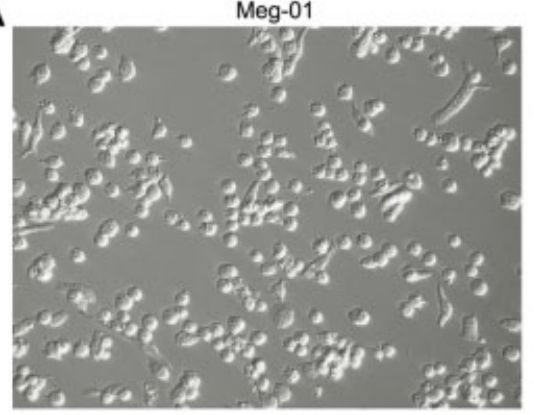

B

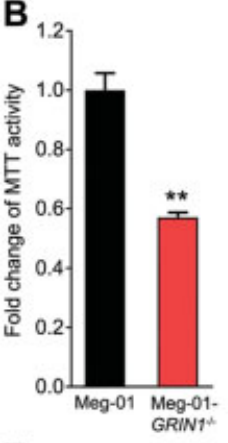

$E_{50}$

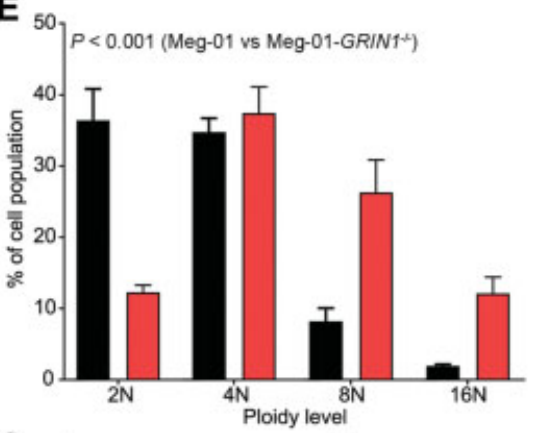

C

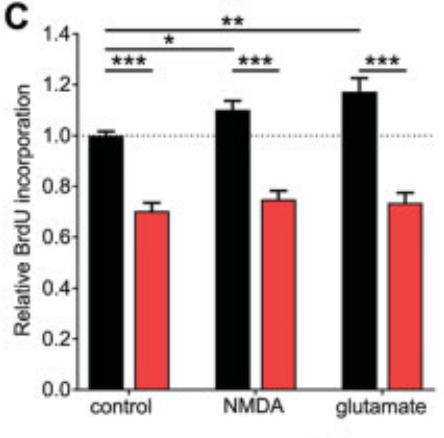

Meg-01-GRIN1

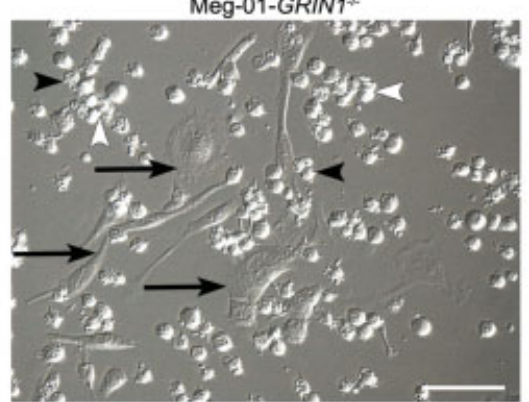

D

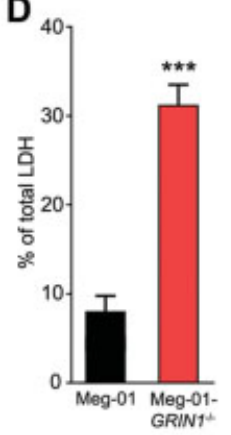

$\mathbf{F}$

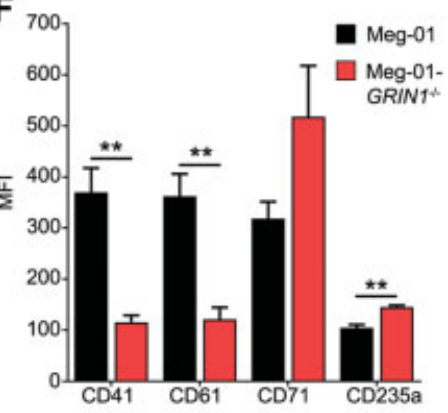

G (i)

(ii)
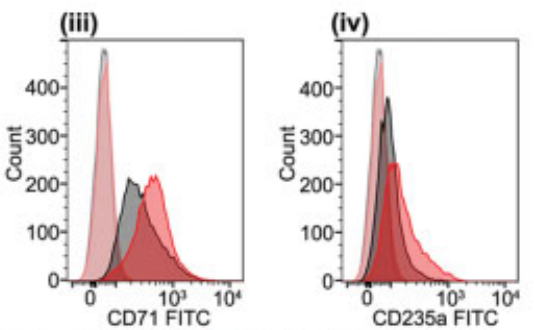

Fig. 2 Effects of GRIN1 deletion on proliferation and differentiation of Meg-01 cells. (A) Representative images of Meg-01 and Meg-01-GRIN1 ${ }^{-/-}$cells taken by Hoffman modulation contrast microscopy. Unmodified Meg-01 cells grew mostly singly in suspension. In comparison, Meg-01-GRIN1 ${ }^{-/-}$cells were larger, more granular and more adherent. Examples of the following features are pointed to in Meg-01-GRIN1 ${ }^{-/}$cells: cell surface budding (black arrowheads); cell clumping (white arrowheads); large, adherent cells, some with cytoplasmic projections (black arrows). Scale bar, $100 \mu \mathrm{m}$ for both. (B-D) Bar graphs showing numbers of viable cells measured by MTT assay (fold change; B), cell proliferation measured by BrdU assay (relative to control; C) and the percentage cell death measured by the cytotoxicity detection (lactate dehydrogenase; LDH) kit (D) in Meg-01 and Meg-01-GRIN1 ${ }^{-1-}$ cells cultured for 3 days. In (C), the effect of NMDAR agonists, NMDA $100 \mu \mathrm{M}$ and glutamate $500 \mu \mathrm{M}$, on cell proliferation is also shown. (E) Nuclear ploidy level (\%) in Meg-01-GRIN1 ${ }^{-/-}$and unmodified Meg-01 cells examined by flow cytometry; $2 \mathrm{~N}, 4 \mathrm{~N}, 8 \mathrm{~N}$ and $16 \mathrm{~N}$ indicate ploidy classes. (F, G) Expression of megakaryocytic and erythroid differentiation markers (CD41a, CD61, CD71 and CD235a) on Meg-01 and Meg-01-GRIN1 ${ }^{-1-}$ examined by flow cytometry; gating is shown in - Supplementary Figs S2,

S5 and S6. G (i-iv) Representative histogram examples of differentiation markers shown in (F), including isotype controls. All bar graphs show mean \pm standard error of the mean from at least three independent experiments. Statistical significance is shown (one-way ANOVA with Dunnett post hoc; $\left.{ }^{*} p<0.05,{ }^{* *} p<0.01,{ }^{* * *} p<0.001\right)$. BrdU, 5-bromo-2-deoxyuridine; MFI, median fluorescent intensity; MTT, 3-(4,5-dimethylthiazol-2-yl)-2,5-diphenyltetrazolium bromide; NMDAR, $N$-methyl-D-aspartate receptor.

Considering that little is known about NMDARs in megakaryocytic cells, we profiled transcriptomic effects of GRIN1 deletion using Clariom S microarrays (- Fig. 6). DE genes were first determined as probe-sets that showed at least a twofold change compared with unmodified Meg-01 cells, with an FDR adjusted $p$-value $\leq 0.05$. The $\mathrm{GO}$ analysis identified 248 genes that were upregulated and 187 genes that were downregulated, with four differentially regulated biological processes, of which "Regulation of developmental process" (GO:0050793) and "Cellular calcium ion homeostasis" (GO:0006874) were the 

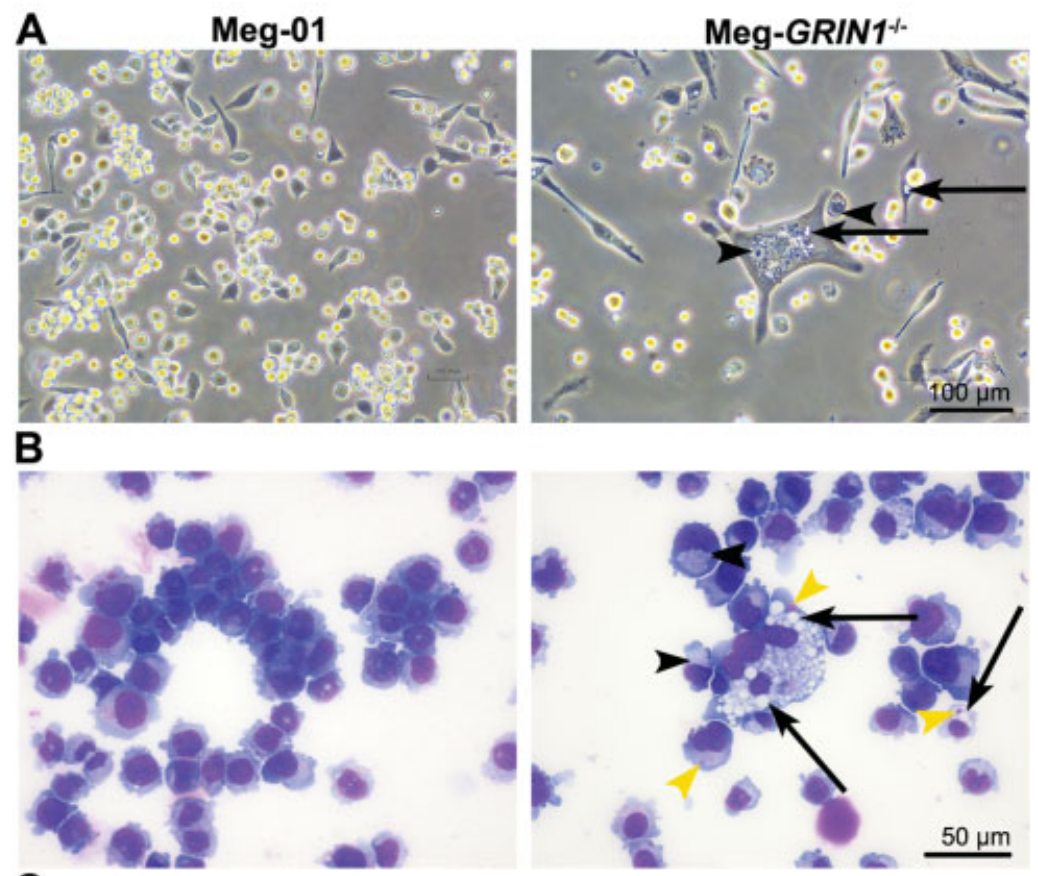

$\mathrm{C}_{\text {(i) }}$

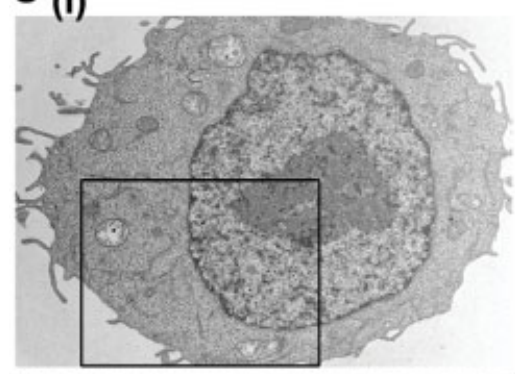

(ii)
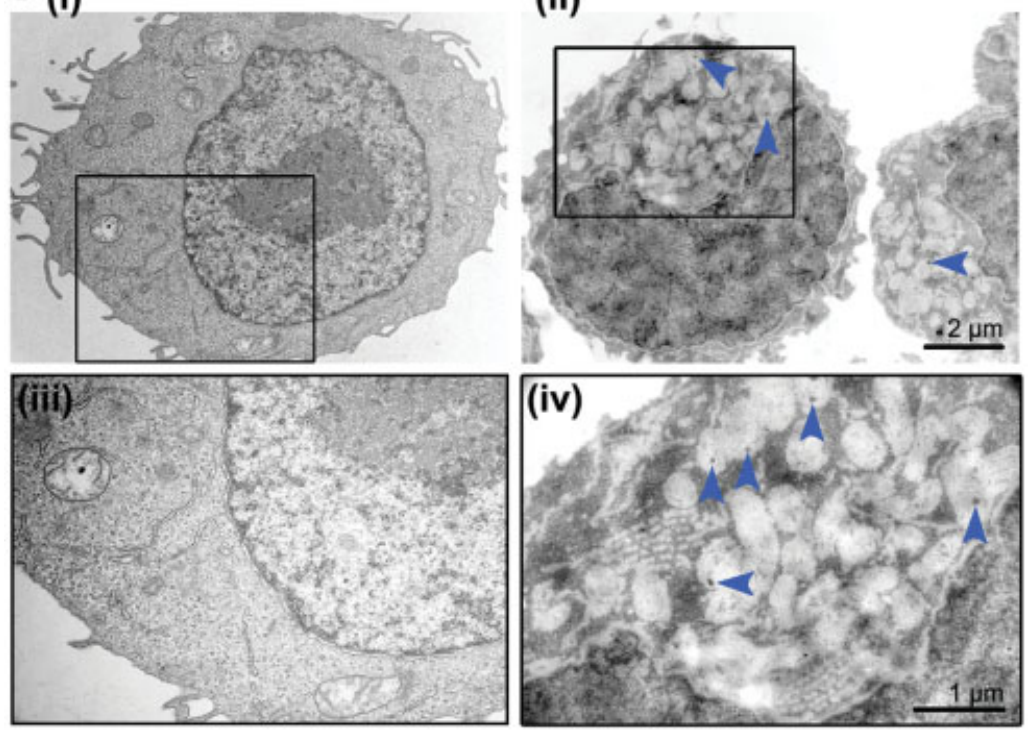

Fig. 3 Cytological effects of GRIN1 knockout in Meg-01 cells. Representative images of cellular morphology of Meg-01 and Meg-01-GRIN1-/cells visualized by phase contrast microscopy (A), bright field microscopy after Wright-Giemsa staining (B), and transmission electron microscopy (C). Examples of the following morphological features are pointed to in Meg-01-GRIN1-/- cells: small, perinuclear cytoplasmic vacuoles (black arrowheads); larger cytoplasmic vacuoles (black arrows); atypical cytoplasmic granules (yellow arrowheads); immature dense granules (blue arrowheads). Frames in $\mathbf{i}$ and ii mark regions enlarged in iii and iv, respectively. Scale bars are shown.

most deregulated ( - Fig. 6A; Supplementary Microarray Excel Data File, available in the online version). Then we analyzed expression of 82 core transcripts of the $\mathrm{Ca}^{2+}$ toolkit, using a list of genes studied in cancer cells before. ${ }^{25}$-Supplementary Table S2 (available in the online version) provides data on the expression of all $\mathrm{Ca}^{2+}$ toolkit genes we analyzed; here, we summarize the most prominent changes ( - Table $\mathbf{1}$ ).

Meg-01-GRIN1 ${ }^{-1-}$ cells showed reduced expression of TRPC6 and CACNA1A (coding for TRPC6 and Cav2.1, respectively), while MCOLN3 (coding for TRP mucolipin 3, TRPML3) was increased (-Table 1). TRPC6 contributes to SOCE in MKs. ${ }^{26}$ The role of Cav2.1 in MKs is unclear, but in erythrocytes Cav2.1 is regulated by TRPC6 and NMDAR. ${ }^{27}$ We also found reduced expression of two genes encoding $\mathrm{Ca}^{2+}$ pumps, ATP2B4 (coding for PMCA4) and ATP2A3 (coding for SERCA3), as well as SLC24A3 (coding for $\mathrm{K}^{+}$dependent $\mathrm{Na}^{+} / \mathrm{Ca}^{2+}$ exchanger 3, NCKX3; - Table 1). The notable changes affecting $\mathrm{Ca}^{2+}$ binding proteins included downregulation of CALN1 (encoding the ER protein, calneuron 1) and upregulation of CALB1 and SCIN (encoding cytosolic calbindin 1 and scinderin, respectively; - Table 1).

Selected microarray data were validated using RT-qPCR in independent passages of Meg-01-GRIN1 ${ }^{-1-}$ cells (- Fig. 6B, 
A

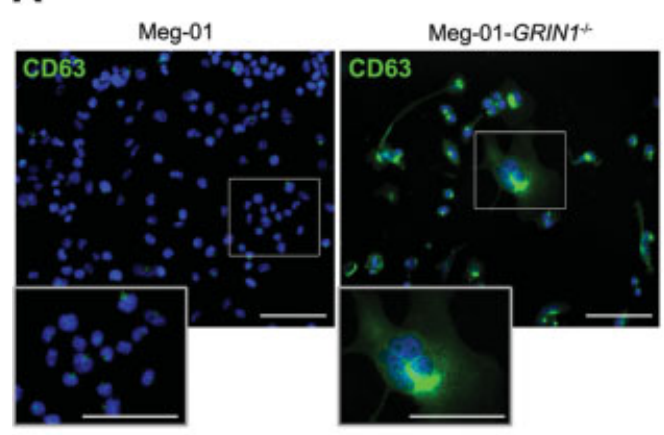

B

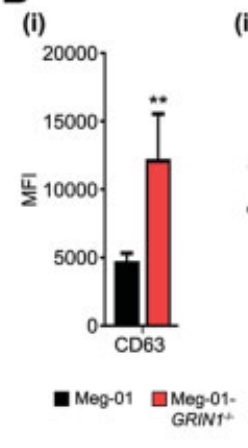

(ii)

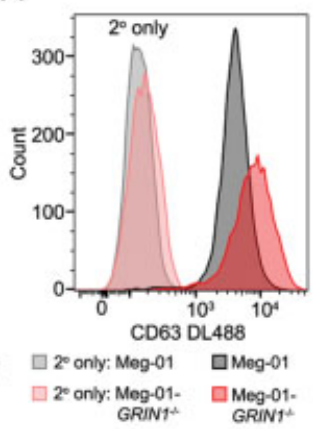

C

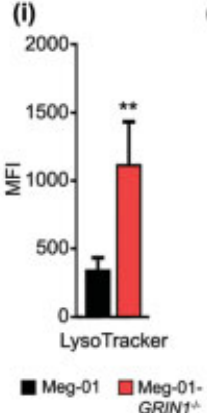

(ii)

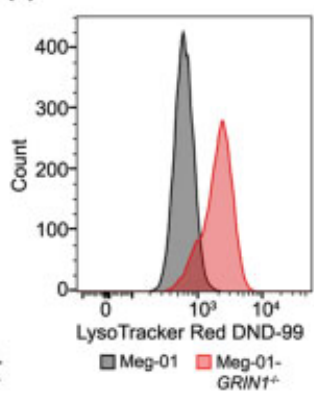

$D_{\text {(i) }}$

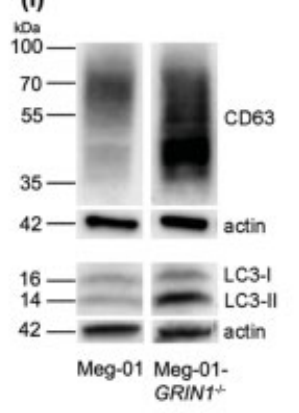

(ii)

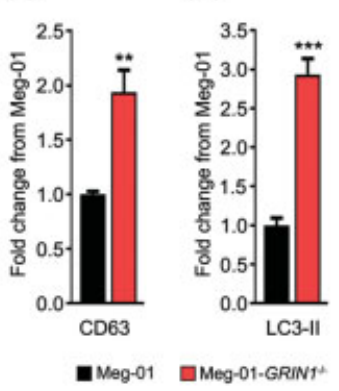

$E_{(i)}$

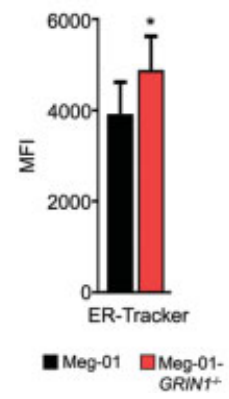

(ii)

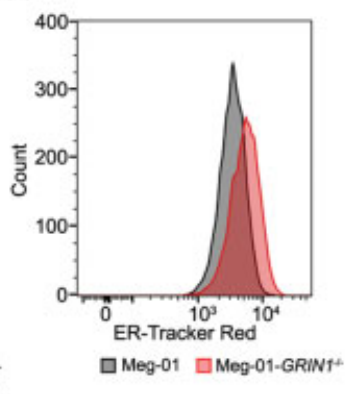

$\mathbf{F}$

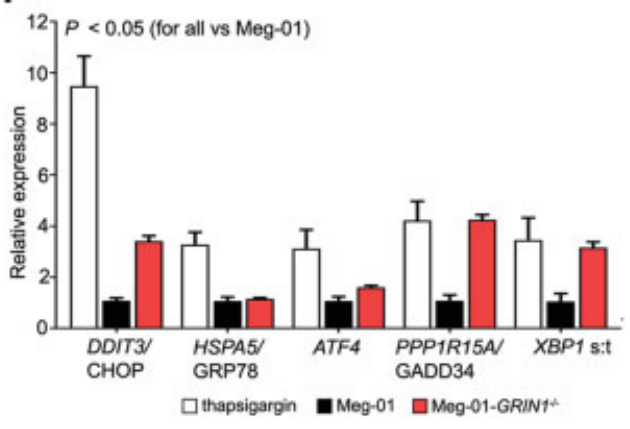

Fig. 4 Cellular stress response pathways examined in Meg-01-GRIN1 ${ }^{-1-}$ cells. (A) Representative images of CD63 immunofluorescence staining in Meg-01 and Meg-01-GRIN1 ${ }^{-/-}$cells visualized by fluorescence microscopy. Scale bars, $100 \mu \mathrm{m}$. (B-E) Bar graphs showing the median fluorescent intensity of CD63 (Bi), LysoTracker Red DND-99 (Ci), and ER-Tracker Red (Ei) in Meg-01 and Meg-01-GRIN1 ${ }^{-/-}$cells examined by flow cytometry. Corresponding histograms of representative examples are shown for CD63 expression including secondary antibody only controls (Bii) and the level of staining for LysoTracker Red DND-99 (Cii) and ER-Tracker Red (Eii). At least three independent experiments were performed for each; gating is shown in - Supplementary Fig S7. (D) Evidence for autophagy induction in Meg-01-GRIN1 ${ }^{-1-}$ cells. Expression of CD63 and lipidation of LC3 in Meg-01 and Meg-01-GRIN1 ${ }^{-1-}$ cells examined by Western blotting (Di). Relative expression of CD63 (normalized to total protein; Dii) and LC3 lipidation (normalized to $\beta$-actin; Diii) was determined by band densitometry in Meg-01-GRIN1 ${ }^{-/-}$cells, relative to Meg-01 cells. Full blots are shown in - Supplementary Fig. S8. Experiments were performed three times in duplicate. (F) Bar graphs showing relative endoplasmic reticulum stress response transcripts examined by RT-qPCR in Meg-01-GRIN1 ${ }^{-1-}$ cells, calculated relative to unmodified Meg-01 cells. Labels include traditional protein names where relevant. Thapsigargin $2 \mu \mathrm{M}$ was used as a positive control. XBP1s:t is the ratio of spliced to total XBP1 transcripts. Four independent experiments were performed in triplicate. All bar graphs show mean \pm standard error of the mean. Statistical significance is shown (Student's $t$-test; ${ }^{*} p<0.05,{ }^{* *} p<0.01,{ }^{* *} p<0.001$ ). NMDAR, $N$-methyl-D-aspartate receptor; RT-qPCR, quantitative reverse transcriptase-polymerase chain reaction.

pink bars), and in unmodified Meg-01 cells after transient knockdown of GRIN1 using esiGRIN1 (-Fig. 6B, white bars), or pharmacologic NMDAR inhibition using memantine (-Supplementary Fig. S11, available in the online version). Both esiGRIN1 and memantine recreated the pattern of changes seen in Meg-01-GRIN1 ${ }^{-1-}$ cells, although esiGRIN1 effects were weaker (-Fig. 6B, white bars), and memantine did not change CALN1 expression (-Supplementary Fig. S11, available in the online version). The effects of memantine argued that altered expression of $\mathrm{Ca}^{2+}$ channels and pumps detected in Meg-01-GRIN1 ${ }^{-1-}$ cells developed due to reduced $\mathrm{Ca}^{2+}$ influx; however, lower expression of CALN1 may have been secondary to a longer term deregulation in intracellular $\mathrm{Ca}^{2+}$ handling induced by GRIN1 deletion. Collectively, our data highlight significant disturbance in the $\mathrm{Ca}^{2+}$ regulatory genes in Meg-01-GRIN1-l- cells, which underscores the important role of NMDAR in $\mathrm{Ca}^{2+}$ homeostasis in the parent cell line. 


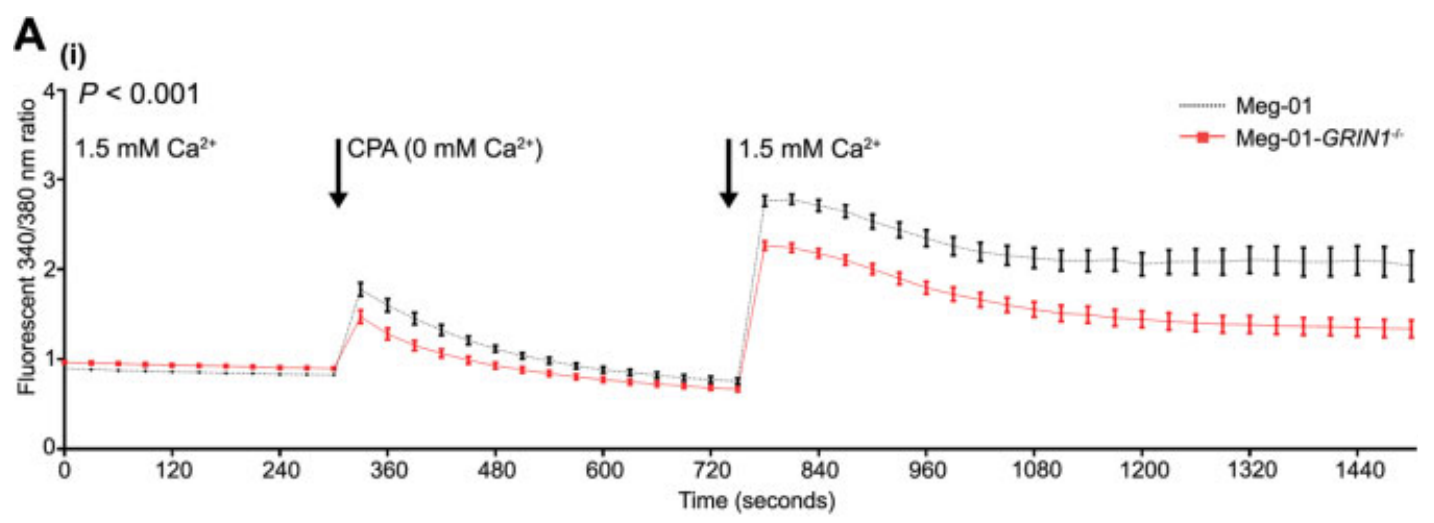

(ii)

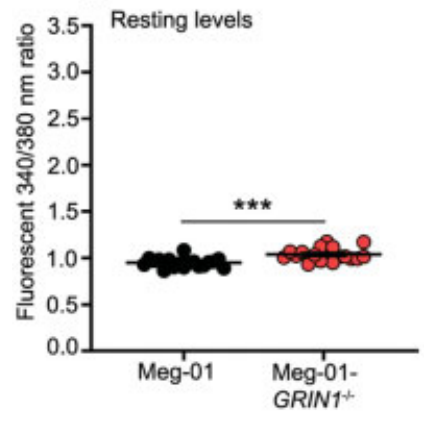

B

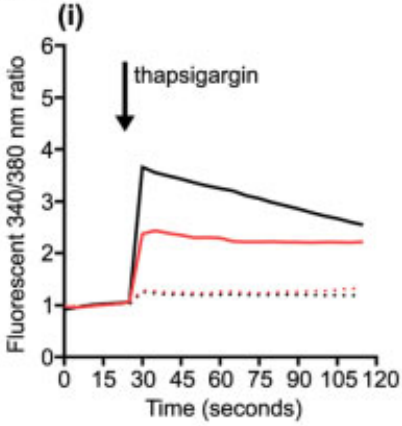

(iii)

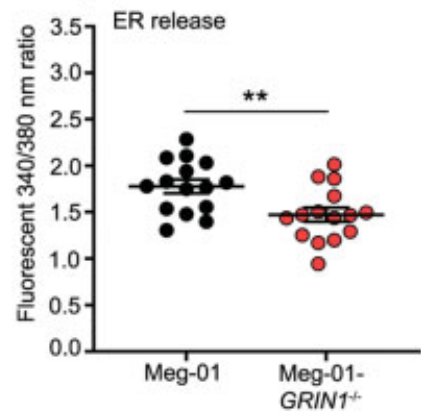

(iv)

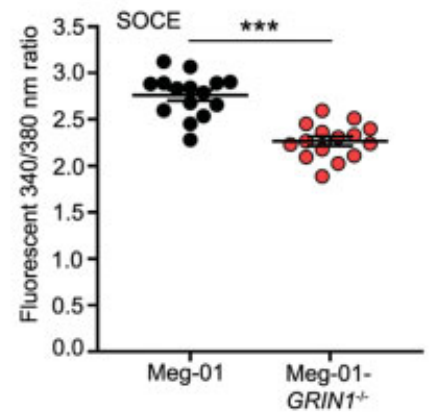

(ii)

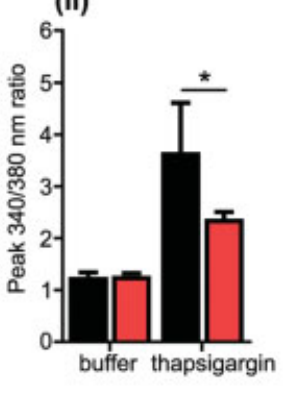

C

(i)

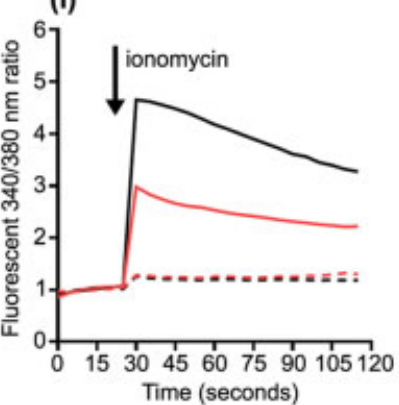

(ii)

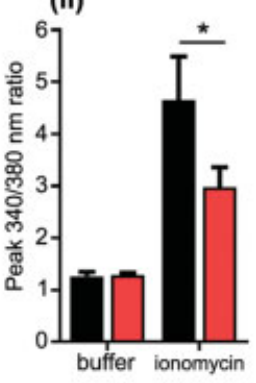

$$
\begin{aligned}
& \text {--- Meg-01: buffer } \\
& \text {--- Meg-01-GRIN1 buffer }
\end{aligned}
$$$$
\begin{aligned}
& \text { - Meg-01: agonist } \\
& \text { - Meg-01-GRIN1+: agonist }
\end{aligned}
$$

Meg-01

$\square$ Meg-01-GRIN1+

Fig. 5 Effects of GRIN1 deletion on intracellular calcium responses in Meg-01 cells. (A-C) Unmodified Meg-01 and Meg-01-GRIN1 ${ }^{-/-}$cells were loaded with Fura2-AM; relative intracellular $\mathrm{Ca}^{2+}$ levels were measured from a fluorescent $340 / 380 \mathrm{~nm}$ ratio. A (i) Line graph shows mean \pm standard error of the mean of the fluorescent $340 / 380 \mathrm{~nm}$ ratio over 1,500 seconds from five independent experiments performed in triplicate. The first 300 seconds reflects relative level of resting cytoplasmic $\mathrm{Ca}^{2+}$ (measured in buffer with $1.5 \mathrm{mM} \mathrm{Ca}^{2+}$ ). At 300 seconds, new buffer was added (containing $0 \mathrm{mM} \mathrm{Ca}{ }^{2+}, 500 \mathrm{nM} \mathrm{EGTA}$, and $\left.10 \mu \mathrm{M} \mathrm{CPA}\right)$ to measure an effect of ER store release; at 750 seconds $1.5 \mathrm{mM} \mathrm{Ca}^{2+}$ was readded and the store-operated Ca ${ }^{2+}$ entry effect was measured. Dotplots generated from Ai show all individual data points for: resting $\mathrm{Ca}^{2+}$ measurements (first 300 seconds [Aii]); CPA-induced maximum responses (at 330 seconds [Aiii]); and peak responses measured after readdition of extracellular $\mathrm{Ca}^{2+}$ (at 780 seconds [Aiv]). In separate experiments, Fura-2-Am loaded cells were stimulated with thapsigargin $2 \mu \mathrm{M}(\mathrm{B})$ or ionomycin $5 \mu \mathrm{g} \mathrm{mL}^{-1}(\mathrm{C})$ in the absence of extracellular $\mathrm{Ca}^{2+}$ to measure an effect of ER Ca ${ }^{2+}$ store release. Buffer indicates control. Line graphs show the mean level of a fluorescent $340 / 380 \mathrm{~nm}$ ratio over 120 seconds. Corresponding bar graphs show the peak level of a fluorescent $340 / 380 \mathrm{~nm}$ ratio during the observation period (mean \pm standard error of the mean). Each experimental condition was repeated five times in triplicate. Statistical significance is shown (Student's t-test; ${ }^{*} p<0.05,{ }^{* *} p<0.01,{ }^{* * *} p<0.001$ ). CPA, cyclopiazonic acid; EGTA, ethylene glycol tetraacetic acid; ER, endoplasmic reticulum.

\section{Transcriptomic Features of Increased Erythroid Differentiation in Meg-01-GRIN1 ${ }^{-I-}$ Cells}

Transcriptome analysis provided further valuable insights into the state of differentiation in Meg-01-GRIN1 ${ }^{-1-}$ cells. The highest expressed transcription factors were HEY1, ZEB1 and JUN (-Table 2). Transcripts of Krueppel-like factors, including $K L F 1$, a master regulator of erythropoiesis were also increased (-Table 2 ). In contrast, transcription factors favoring megakaryopoiesis (in particular RUNX1, FLI1, ERG and MEIS1) were reduced ( - Table 2). This pattern aligns with reduced megakaryocytic and increased erythroid differentiation we observed in Meg-01-GRIN1 ${ }^{-1-}$ cells. In keeping with the levels of transcriptional regulators, transcripts of molecules associated with megakaryocytic differentiation (e.g. platelet-associated glycoproteins) were lower, but erythroid transcripts (e.g. embryonic haemoglobins and red cell 
A

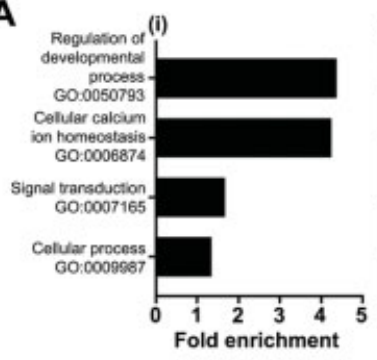

B

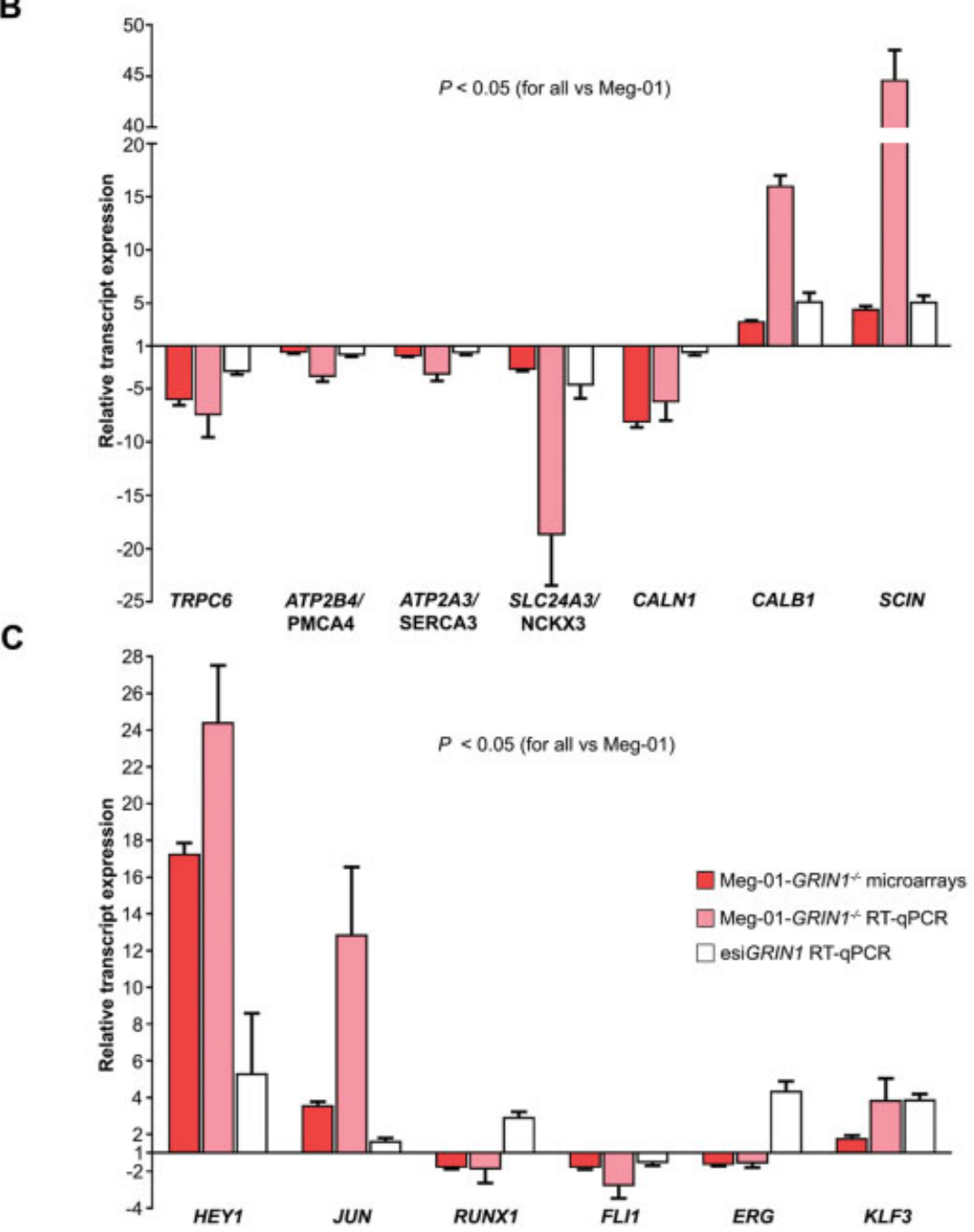

Fig. 6 Transcriptomic changes in Meg-01-GRIN1 ${ }^{-/-}$cells determined from Clariom S microarrays. (A) Biological processes altered in Meg-01-GRIN1 ${ }^{-/-}$cells are shown, identified by GO enrichment analysis performed with the PANTHER tool, using the PANTHER GO-Slim biological process annotation dataset with FDR $\leq 0.05$ and fold change $\geq 2$. (Ai) Fold enrichment of GO term from reference. (ii) Statistical significance of GO term shown as -log ( $p$-value). (iii) Percentage of genes in the list that were differentially expressed. Numbers on the far right indicate genes differentially expressed over all genes in the pathway. (B, C) Bar graphs showing relative transcript levels of selected genes involved in the $\mathrm{Ca}^{2+}$ toolkit (B) and deregulated transcription factors (C) detected by microarrays using FDR $\leq 0.05$ and fold change change $\geq 1.5$ (red bars), followed by validation by RT-qPCR in independent biological samples (pink bars), and after treatment with esiGRIN1 (white bars), all calculated relative to unmodified Meg-01 cells. Positive values indicate increased, and negative values reduced gene expression levels in Meg-01-GRIN1 ${ }^{-1-}$ cells compared with unmodified Meg-01 cells. In transient knockdown experiments, Meg-01 cells were cultured in the presence of esiGRIN1 for 3 days. Experiments were repeated three times. Bars are mean \pm standard error of the mean. Labels include traditional protein names where relevant. Statistical significance is shown; Fisher's exact test with FDR correction for (A) and one-way ANOVA with Dunnett posthoc for (B) and (C). All differences in expression shown in (B) and (C) were statistically significant compared with unmodified Meg-01 cells. FDR, false discovery rate; GO, gene ontology; RT-qPCR, quantitative reverse transcriptase-polymerase chain reaction; esiGRIN1, Meg-01 cells treated with esi (endoribonuclease-prepared short interfering) RNA targeting GRIN1 gene.

membrane proteins) were higher in Meg-01-GRIN1 ${ }^{-1-}$ cells compared with unmodified Meg-01 cells (-Supplementary Table 53, available in the online version).
Selected changes in transcription factors were confirmed using RT-qPCR (-Fig. 6C, pink bars). Effects of esiGRIN1 were also tested ( $\mathbf{- F i g . 6 C}$, white bars), which showed that 
Table 1 Differential expression of the $\mathrm{Ca}^{2+}$ toolkit molecules in Meg-01-GRIN1 ${ }^{-1-}$ cells compared with unmodified Meg-01 cells determined from Clariom S microarrays

\begin{tabular}{|l|l|l|l|l|}
\hline Gene name & Calcium toolkit molecule & Fold change & $p$-Value & FDR \\
\hline SCIN & Scinderin & 4.85 & $1.64 \mathrm{E}-07$ & $2.41 \mathrm{E}-05$ \\
\hline CALB1 & Calbindin 1 & 3.73 & $5.26 \mathrm{E}-08$ & $1.05 \mathrm{E}-05$ \\
\hline MCOLN3 & Transient receptor potential mucolipin 3 channel & 2.64 & 0.0003 & 0.0056 \\
\hline ATP2B4 & Plasma membrane Ca ${ }^{2+}$ ATPase 4 & -1.78 & 0.0004 & 0.0066 \\
\hline ATP2A3 & Sarco-/endoplasmic reticulum Ca ${ }^{2+}$ ATPase 3 & -1.99 & $1.04 \mathrm{E}-07$ & $1.71 \mathrm{E}-05$ \\
\hline CACNA1A & Voltage-gated calcium channel 2.1 & -2.26 & 0.0007 & 0.0107 \\
\hline SLC24A3 & $\mathrm{K}^{+}$-dependent Na ${ }^{+}$Ca $^{2+}$ exchanger 3 & -2.97 & $1.42 \mathrm{E}-08$ & $4.29 \mathrm{E}-06$ \\
\hline TRPC6 & Transient receptor potential channel 6 & -6.61 & $9.69 \mathrm{E}-10$ & $6.31 \mathrm{E}-07$ \\
\hline CALN1 & Calneuron 1 & -8.38 & $1.24 \mathrm{E}-10$ & $1.84 \mathrm{E}-07$ \\
\hline
\end{tabular}

Abbreviation: FDR, false discovery rate.

similar to Meg-01-GRIN1 ${ }^{-1-}$ cells, transcript levels of HEY1 and KLF3 were increased 3 days after transfections, and FLI1 transcripts were reduced. However, RUNX1 and ERG levels were higher, and JUN levels increased only slightly upon esiGRIN1 treatment, suggesting that changes in Meg-01GRIN1 ${ }^{-1-}$ cells were time dependent $(-$ Fig. $6 \mathbf{6 C}$ ). The small upregulation of JUN in short-term experiments with esiGRIN1 appeared consistent with the known, secondary role of JUN after ER stress that we saw in Meg-01-GRIN1-Icells. ${ }^{28}$

The dominant expression of the erythroid transcription factor, KLF3 persisted in Meg-01-GRIN1 ${ }^{-1-}$ cells after culture with PMA ( - Supplementary Fig. S12A, available in the online version). Megakaryocytic differentiation also increased, as it is known to occur in unmodified Meg-01 cells in the presence of PMA (- Supplementary Figs S12B, S13 and S14, available in the online version). ${ }^{14,29}$ PMA did not affect expression of TRPC6, SLC24A3 and CALN1 in Meg-01-GRIN1 ${ }^{-1-}$ cells; however, additional alterations occurred in ATP2B4, ATP2A3 and CALB1, which largely followed the direction of change induced by PMA in unmodified Meg-01 cells (-Supplementary Fig. S12C, available in the online version). PKC is known to impact $\mathrm{Ca}^{2+}$ signaling and interact with $\mathrm{Ca}^{2+}$ pathways to induce its full transcriptional effect. Thus, PMA effects appeared in keeping with a cross-talk between PKC and $\mathrm{Ca}^{2+}$ pathways during megakaryocytic-erythroid differentiation. ${ }^{2,30}$

Table 2 Differential expression of transcriptional regulators in Meg-01-GRIN1-/- cells compared with unmodified Meg-01 cells determined from Clariom S microarrays

\begin{tabular}{|c|c|c|c|c|}
\hline Gene name & Transcription factor/regulator & Fold change & p-Value & FDR \\
\hline HEY1 & Hes related family basic helix-loop-helix transcription factor with YRPW motif 1 & 16.65 & 1.36E-11 & 4.84E-08 \\
\hline ZEB1 & Zinc finger E-box binding homeobox 1 & 16.42 & $5.24 \mathrm{E}-12$ & $4.84 \mathrm{E}-8$ \\
\hline JUN & Jun proto-oncogene & 3.47 & $5.21 \mathrm{E}-06$ & $3.00 \mathrm{E}-04$ \\
\hline ID1 & Inhibitor of DNA binding 1 & 3.16 & $7.88 \mathrm{E}-09$ & $3.02 \mathrm{E}-06$ \\
\hline ID3 & Inhibitor of DNA binding 2 & 3.03 & $2.29 \mathrm{E}-05$ & $9.00 \mathrm{E}-04$ \\
\hline EGR1 & Early growth response 1 & 2.67 & 4.80E-07 & $5.32 \mathrm{E}-05$ \\
\hline HEY2 & Hes related family BHLH transcription factor with YRPW motif 2 & 2.27 & 7.69E-07 & 7.63E-05 \\
\hline PAX6 & Paired box 6 & 2.28 & 0.0141 & 0.0926 \\
\hline KLF3 & Kruppel like factor 3 & 1.93 & 4.24E-05 & $1.40 \mathrm{E}-03$ \\
\hline KLF6 & Kruppel like factor 6 & 1.72 & 2.47E-05 & $9.00 \mathrm{E}-04$ \\
\hline CREBRF & CREB3 regulatory factor & 1.68 & 7.96E-05 & 0.0023 \\
\hline NFATC1 & Nuclear factor of activated T-cells, cytoplasmic, calcineurin-dependent 1 & 1.7 & $6.76 \mathrm{E}-05$ & 0.0020 \\
\hline KLF1 & Kruppel like factor 1 & 1.57 & $9.12 \mathrm{E}-05$ & $2.50 \mathrm{E}-03$ \\
\hline KLF10 & Kruppel like factor 10 & 1.56 & $1.00 \mathrm{E}-04$ & $2.80 \mathrm{E}-03$ \\
\hline$E R G$ & ETS transcription factor ERG & -1.67 & $2.70 \mathrm{E}-06$ & $2.00 \mathrm{E}-04$ \\
\hline FLI1 & FLI-1 proto-oncogene & -1.83 & $9.98 \mathrm{E}-07$ & $9.27 \mathrm{E}-05$ \\
\hline RUNX1 & Runt related transcription factor 1 & -1.85 & 1.57E-06 & $1.00 \mathrm{E}-04$ \\
\hline MEIS1 & Meis homeobox 1 & -1.98 & $3.43 \mathrm{E}-06$ & 0.0002 \\
\hline
\end{tabular}

Abbreviation: FDR, false discovery rate. 


\section{Memantine Increases Cytarabine-Mediated Cell Killing of Meg-01 Cells}

The increased levels of cytoplasmic $\mathrm{Ca}^{2+}$, ER stress response, autophagy induction, and higher LDH release suggested that Meg-01-GRIN1 ${ }^{-1-}$ cells had a lower threshold for cell death. We hypothesized this pro-death state would make cells more vulnerable to additional toxic insults, and tested if NMDAR inhibition would increase cell killing by cytarabine (currently, a cornerstone of antileukemia treatment). Memantine was employed in these experiments, as it is an approved drug used in neurological patients. Meg-01 cells were pretreated with $100 \mu \mathrm{M}$ memantine for 1 hour, followed by 3 days with $0.1 \mu \mathrm{M}$ (low dose) cytarabine; effects on cell numbers were tested using an MTT assay ( - Fig. 7). Even this brief exposure to memantine resulted in 3.1-times more cell killing compared with cytarabine alone (-Fig. 7 ).

\section{Discussion}

This study provides the first evidence that NMDARs comprise an integral component of the $\mathrm{Ca}^{2+}$ toolkit in Meg-01 cells, with NMDAR function required to prevent cell stress and support megakaryocytic over erythroid differentiation.

CRISPR-Cas9-mediated NMDAR hypofunction caused marked changes in $\mathrm{Ca}^{2+}$ homeostasis in Meg-01 cells, resulting in atypical differentiation, basal ER stress and cell death. Meg-01-GRIN1 ${ }^{-1-}$ cells accumulated lysosomerelated organelles, suggesting abnormalities in membrane trafficking. Resting cytosolic $\mathrm{Ca}^{2+}$ levels were higher in Meg-01-GRIN1 ${ }^{-1-}$ cells, but ER $\mathrm{Ca}^{2+}$ release and SOCE were lower after activation. GRIN1 deletion affected the transcription of the following $\mathrm{Ca}^{2+}$ toolkit genes: TRPC6, CACNA1A, MCOLN3, ATP2A3, ATP2B4, SLC24A3, CALN1, CALB1 and SCIN; most of which also changed in response to memantine. Increased levels of JUN, DDIT3, ATF4, PPP1R15A and XBP1 spliced transcripts indicated ER stress, and a shift in megakaryocytic-erythroid transcription factors explained features of erythroid differentiation. Finally, pharmacologic NMDAR inhibition using memantine increased cell killing by cytarabine.

Despite increasing evidence that pharmacologic NMDAR inhibitors disturb megakaryocytic maturation, ${ }^{8,10-12}$ NMDAR roles in MKs remained speculative. Our work adds solid evidence that NMDARs operate as important components of the $\mathrm{Ca}^{2+}$ toolkit in Meg-01 cells; hence, further analysis in normal and malignant MKs may uncover meaningful NMDAR roles. Similar to the NMDAR, several other components of the $\mathrm{Ca}^{2+}$ toolkit found differentially expressed in Meg-01-GRIN1-1 cells (e.g. TRPC6, CACNA1A, MCOLN3, CALN1 and CALB1) are best known for their neuronal functions. Our results suggest that these molecules have previously unappreciated roles in megakaryocytic and erythroid differentiation.

Recent work provided computational support for the NMDAR involvement in human erythropoiesis. The GRIN3B gene, encoding the GluN3B subunit of NMDAR, has been linked with signaling through ErbB4 (epidermal growth factor receptor Erb-B2 receptor tyrosine kinase 4), which balances erythropoiesis against other myeloid lineages (in

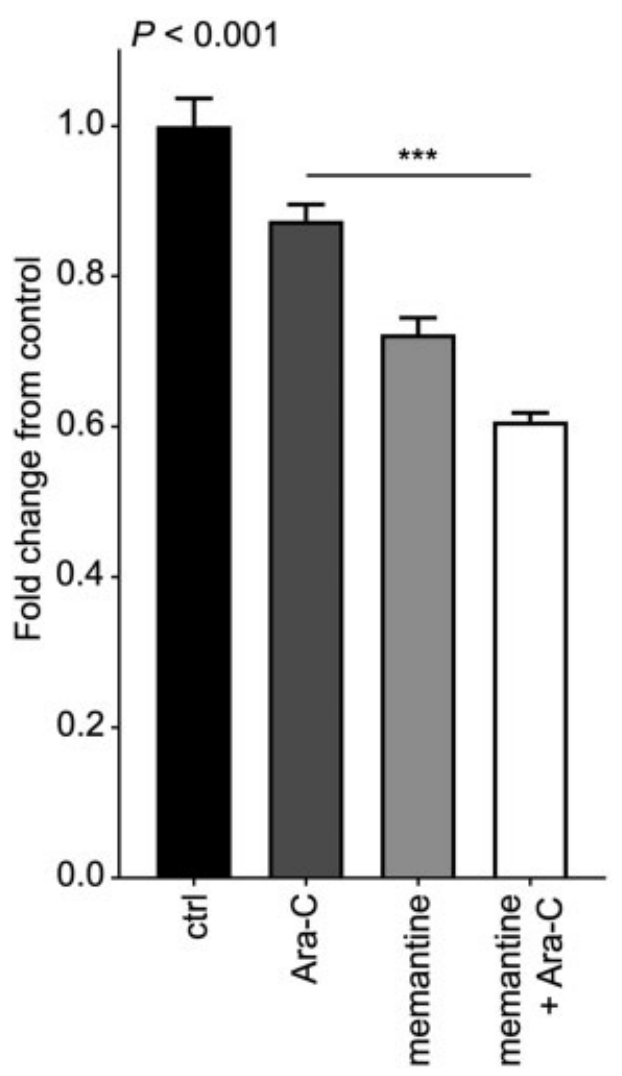

Fig. 7 Effect of memantine on cytarabine-induced cell killing of Meg01 cells. Meg-01 cells were pretreated with memantine $100 \mu \mathrm{M}$ for 1 hour and then cultured with cytarabine (Ara-C; $100 \mathrm{~nm}$ ) for 3 days. Cell viability was measured by MTT assay. Bars are mean \pm standard error of the mean from four independent experiments each in triplicate. Statistical significance is shown (one-way ANOVA with Dunnet post hoc; $\left.{ }^{* * *} p<0.001\right)$. Ara-C, cytarabine; ctrl, control; MTT, 3(4,5-dimethylthiazol-2-yl)-2,5-diphenyltetrazolium bromide.

particular megakaryopoiesis) in multiple in vivo and ex vivo models. ${ }^{31}$ Our results are consistent with these data. Using Meg-01 cell line that carries dual, megakaryocytic-erythroid differentiation potential, we provide the first experimental evidence that NMDARs and intracellular $\mathrm{Ca}^{2+}$ homeostasis balance megakaryocytic and erythroid cell fates.

Differentiation of megakaryocytic and erythroid lineages are closely connected and regulated by a set of transcription factors that include RUNX1, ERG, FLI1, GATA and KLF family members. ${ }^{32}$ RUNX1 increases megakaryocytic and represses erythroid differentiation by antagonising the erythroid master regulator KLF1. ${ }^{33}$ The converse is also true, as KLF1 inhibits megakaryopoiesis. ${ }^{34}$ We found that KLF1, KLF3, KLF6 and KLF10 were expressed to higher levels in Meg01-GRIN1 ${ }^{-1-}$ cells, GATA1 and GATA2 were unchanged, and RUNX1, FLI1, ERG and MEIS1 were expressed to lower levels compared with control Meg-01 cells, consistent with the phenotypic bias toward erythropoiesis detected in Meg-01GRIN1 ${ }^{-I-}$ cells. Based on CD41 and CD235a expression, Meg01-GRIN1 ${ }^{-1-}$ cells were heterogeneous (including erythroid, megakaryocytic, and double-positive cells; - Supplementary Fig. S12Bii, available in the online version) that may explain the discrepancy between their higher ploidy and lower CD41/CD61 expression for the overall population. 
We do not know what mechanisms were responsible for transcription factor alterations in Meg-01-GRIN1 ${ }^{-1-}$ cells. Microarray analysis showed NFATC1 transcript levels were higher (-Table 2), but there was no transcriptional signature of enhanced NFAT activity (data not shown). Other pathways through which NMDARs regulate transcription include calcium / calmodulin-dependent protein kinases (CaMK). ${ }^{35}$ Expression of CAMKIV was reduced in Meg-01-GRIN1 ${ }^{-1-}$ cells (FC -1.91 ; Supplementary Microarray Excel Data File, available in the online version), raising the possibility that this pathway is operational in MKs, but functional validation is required.

This is not the first study to report that a membranous $\mathrm{Ca}^{2+}$ channel affects the balance of megakaryocytic-erythroid differentiation. Overexpression of TRPA1 (ankyrin 1; a TRPC family channel that contributes to SOCE in Meg-01 cells ${ }^{36}$ ) was shown to suppress erythroid but enhance megakaryocytic differentiation in K-562 and HEL cell lines; however, the mechanism of TRPA1 action was not examined in that study. ${ }^{37}$ Our findings are in agreement, showing the reciprocal effect, as reduced NMDAR function enhances erythroid differentiation. Therefore, similar to TRPA1, normal NMDAR activity favors megakaryocytic differentiation. Previous authors suggested therapeutic opportunities involving modulation of TRPA1 in disorders associated with anemia and thrombocytopenia. ${ }^{37}$ Our results suggest that NMDAR (and possibly other components of the $\mathrm{Ca}^{2+}$ toolkit) may provide similar opportunities. As a proof of principle, we show that memantine, a drug used to treat neurological patients, increases Meg-01 cell killing by cytarabine, suggesting a drug combination for further testing in primary cells.
Based on what is known about normal functions of the $\mathrm{Ca}^{2+}$ toolkit genes, we propose the following changes compensated for the NMDAR hypofunction in Meg-01 cells (-Fig. 8). Reduced expression of TRPC6 and CANA1A restricted $\mathrm{Ca}^{2+}$ influx across the plasma membrane. Lower levels of ATP2A3 and CALN1 transcripts reduced ER $\mathrm{Ca}^{2+}$ stores, ${ }^{38}$ implying that overall Meg-01-GRIN1 ${ }^{-1-}$ cells experienced a form of $\mathrm{Ca}^{2+}$ "starvation." However, resting $\mathrm{Ca}^{2+}$ levels were higher in Meg01-GRIN1 ${ }^{-1-}$ cells, suggesting an alternative mechanism to increase cytosolic $\mathrm{Ca}^{2+}$ levels. Higher expression of MCOLN3 may contribute $\mathrm{Ca}^{2+}$ efflux from immature lysosomal organelles that accumulated in Meg-01-GRIN1 ${ }^{-1-}$ cells. ${ }^{39}$ In support, glutamate recruits lysosomal $\mathrm{Ca}^{2+}$ stores in neurons and glia. ${ }^{40}$ In addition, lower levels of ATP2A3, ATP2B4 and SLC24A3 transcripts may reduce exclusion of cytosolic $\mathrm{Ca}^{2+}$ into the ER and the extracellular compartment, respectively. Increased cytosolic $\mathrm{Ca}^{2+}$ levels observed in Meg-01-GRIN1 ${ }^{-1-}$ cells were likely required to preserve signaling, but also implied a stressed, pro-apoptotic cell state. It is possible that higher expression of CALB1 rescued Meg-01-GRIN1 ${ }^{-1-}$ cells from apoptosis, ${ }^{41,42}$ and SCIN contributed to differentiation. ${ }^{43}$ Overall, the range of transcriptomic changes we found in Meg-01GRIN1 $^{-1-}$ cells indicate that NMDARs work together with other $\mathrm{Ca}^{2+}$ channels, such as TRPC6, Cav2.1 and TRPML3 located in the plasma and lysosomal membranes respectively, to support $\mathrm{Ca}^{2+}$ signaling in Meg-01 cells (-Fig. 8).

The increase in lysosomal organelles and associated MCOLN3 upregulation in Meg-01-GRIN1 ${ }^{-1-}$ cells are intriguing. Lysosomes and platelet dense granules share

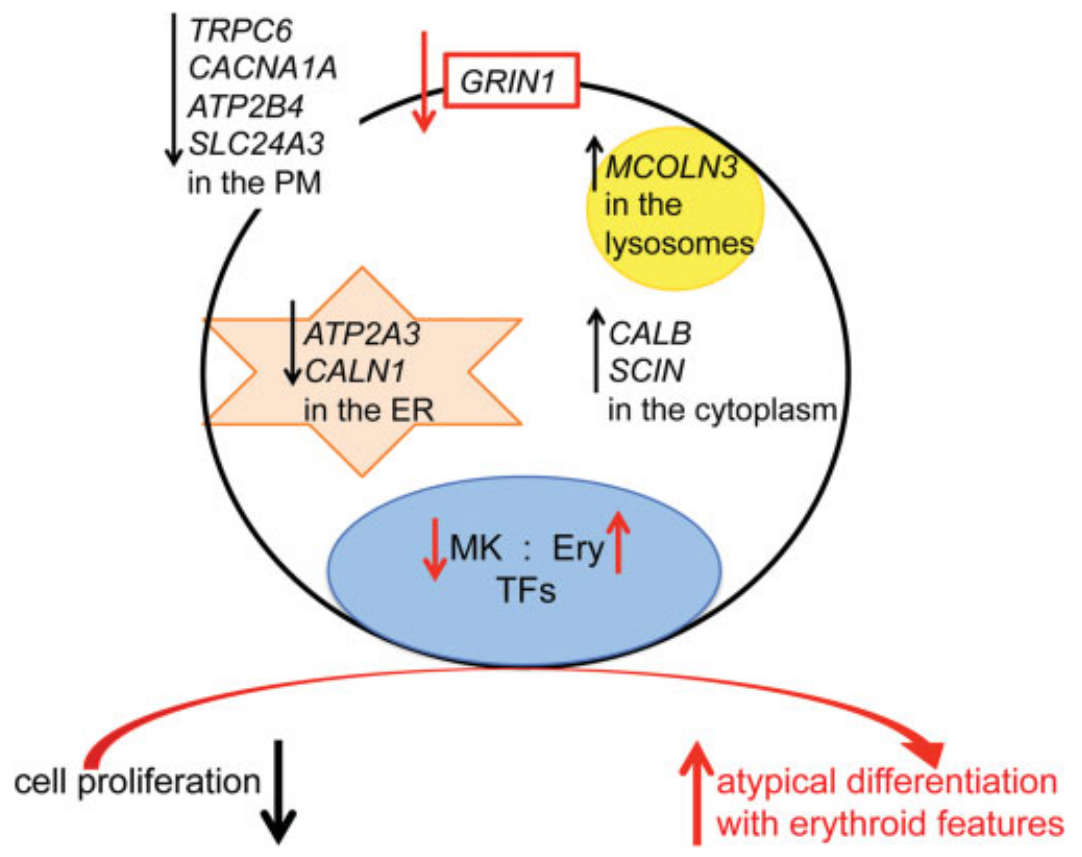

Fig. 8 Schematic summary of the changes caused by GRIN1 deletion in Meg-01 cells. GRIN1 deletion in Meg-01 cells induced NMDAR hypofunction that led to the significant remodeling of the $\mathrm{Ca}^{2+}$ regulatory network associated with atypical differentiation showing erythroid features. Reduced expression of TRPC6 and CACNA1A had the potential to reduce $\mathrm{Ca}^{2+}$ entry from the extracellular environment. Lower levels of ATP2A3 and CALN1 could reduce ER Ca ${ }^{2+}$ stores, leading to ER stress. Lower levels of ATP2A3, ATP2B4 and SLC24A3, and higher levels of MCOLN3 had the potential to increase cytoplasmic $\mathrm{Ca}^{2+}$ levels, buffered by increased expression of CALB1. Higher levels of SCIN could assist differentiation. GRIN1 deletion also altered expression of selected hematopoietic transcription factors, demonstrating a decrease in megakaryocytic but an increase in erythroid regulators, in keeping with increased erythroid differentiation of Meg-01-GRIN1 ${ }^{-/-}$cells. The subcellular sites of expression indicated on the schematic apply to the proteins encoded by the genes shown. ER, endoplasmic reticulum; Ery, erythroid; MK, megakaryocytic; PM, plasma membrane; TF, transcription factor. 
biogenesis ${ }^{44,45}$ and secretion mechanisms. ${ }^{46}$ TRPML3 is expressed in early lysosomes where it regulates $\mathrm{Ca}^{2+}$ efflux and related membrane trafficking. ${ }^{39}$ Our evidence for increased lysosomal and ER accumulation in Meg-01-GRIN1 ${ }^{-1-}$ cells corroborates previous findings by our group and others of increased cytoplasmic vacuolation arising in megakaryocytic cells in the presence of NMDAR inhibitors. ${ }^{10-12}$ To our knowledge, this is the first study to report potential NMDAR contribution to lysosomal biogenesis in megakaryocytic cells.

Our study has several limitations. The phenotype of Meg01-GRIN1 $1^{-I}$ cells may be contributed by other mechanisms that occurred downstream or independently of reduced $\mathrm{Ca}^{2+}$ influx through the NMDAR. We did not dissect the roles of individual molecular changes we found, and cannot depict NMDAR pathways in megakaryocytic cells. Our results raise the possibility that NMDARs regulate $\mathrm{Ca}^{2+}$ storage/release from the lysosomal organelles, but no measurements of lysosomal $\mathrm{Ca}^{2+}$ were performed. Our conclusions are derived from studies in one, one cell line. Meg-01 cells were chosen based on our previous findings showing that they are better suited than K-562 and Set- 2 cells to study NMDAR function. However, more detailed characterization of the $\mathrm{Ca}^{2+}$ toolkit is required using other models of megakaryocytic and erythroid differentiation. Examination of the $\mathrm{Ca}^{2+}$ toolkit may also be rewarding in myeloproliferative neoplasms, as CALR gene mutations are predicted to reduce $\mathrm{Ca}^{2+}$ binding in the $\mathrm{ER}^{47}$ which could trigger ER stress, recently revealed in patient cells. ${ }^{48}$

In summary, CRISPR-Cas9-mediated GRIN1 deletion disturbed $\mathrm{Ca}^{2+}$ homeostasis in Meg-01 cells and shifted differentiation toward the erythroid lineage. The downstream effects of the reduced NMDAR function involved changes in $\mathrm{ER} \mathrm{Ca}^{2+}$ release, lysosome-related organelles, $\mathrm{Ca}^{2+}$ toolkit molecules, and megakaryocytic-erythroid transcription factors. Our findings strengthen the evidence for the importance of NMDAR and intracellular $\mathrm{Ca}^{2+}$ homeostasis in megakaryocytic cell function, including balancing of ER stress and megakaryocytic-erythroid differentiation.

\section{What is known about this topic?}

- Intracellular signaling by calcium ions $\left(\mathrm{Ca}^{2+}\right)$ supports differentiation of normal megakaryocytes.

- $\mathrm{N}$-methyl-D-aspartate receptors (NMDARs) appear to operate as $\mathrm{Ca}^{2+}$ channels in megakaryocytic cells.

\section{What does this paper add?}

- We provide the first genetic evidence that NMDARs are an integral component of the $\mathrm{Ca}^{2+}$ toolkit in megakaryocytic cells.

- NMDARs favor megakaryocytic over erythroid differentiation, support dense granule biogenesis, and contribute to $\mathrm{Ca}^{2+}$ homeostasis in the endoplasmic reticulum.

- Modulation of $\mathrm{Ca}^{2+}$ homeostasis offers potential to inhibit proliferation of malignant megakaryocytes and increase erythroid differentiation.

\section{Authors' Contributions}

M.L.K.Z designed the study. J.I.H., T.N.G., M.C., Y.N.S.N., L.L. and M.L.K.Z generated and analysed data. N.C., C.B., R.C.P., D.C.S., S.K.B. and M.L.K.Z provided methodology advice, supervision and mentorship. J.I.H., T.N.G. and M.L.K.Z wrote the manuscript. All authors edited the manuscript and approved the final version for submission.

Note

J.I.H. received PhD scholarship from Anne and Victoria Norman, supplemented by payments from the Marijana Kumerich Trust.

\section{Funding}

This work was funded by Auckland Medical Research Foundation, Leukemia \& Blood Cancer New Zealand, and Cancer Research Trust.

Conflict of Interest

None declared.

\section{Acknowledgments}

Jacqueline Ross and Hilary Holloway (Biomedical Imaging Research Unit) helped with electron microscopy. Stephen Edgar (Molecular Medicine and Pathology) and Michelle Petrasich (LabPlus) supported flow cytometry work. Liam Williams (New Zealand Genomics Limited) processed Clariom S microarrays. We are grateful to Dr Elizabeth Ledgerwood for helpful discussions and comments on the manuscript.

\section{References}

1 Berridge MJ, Bootman MD, Roderick HL. Calcium signalling: dynamics, homeostasis and remodelling. Nat Rev Mol Cell Biol 2003;04(07):517-529

2 Di Buduo CA, Balduini A, Moccia F. Pathophysiological significance of store-operated calcium entry in megakaryocyte function: opening new paths for understanding the role of calcium in thrombopoiesis. Int J Mol Sci 2016;17(12):17

3 Berridge MJ. Inositol trisphosphate and calcium signalling mechanisms. Biochim Biophys Acta 2009;1793(06):933-940

4 Clapham DE. Calcium signaling. Cell 2007;131(06):1047-1058

5 Zaslavsky A, Chou ST, Schadler K, et al. The calcineurin-NFAT pathway negatively regulates megakaryopoiesis. Blood 2013;121 (16):3205-3215

6 Di Buduo CA, Moccia F, Battiston M, et al. The importance of calcium in the regulation of megakaryocyte function. Haematologica 2014;99(04):769-778

7 Wang JX, Furukawa H. Dissecting diverse functions of NMDA receptors by structural biology. Curr Opin Struct Biol 2019; 54:34-42

8 Genever PG, Wilkinson DJ, Patton AJ, et al. Expression of a functional N-methyl-D-aspartate-type glutamate receptor by bone marrow megakaryocytes. Blood 1999;93(09):2876-2883

9 Traynelis SF, Wollmuth LP, McBain CJ, et al. Glutamate receptor ion channels: structure, regulation, and function. Pharmacol Rev 2010;62(03):405-496

10 Kamal T, Green TN, Morel-Kopp MC, et al. Inhibition of glutamate regulated calcium entry into leukemic megakaryoblasts reduces cell proliferation and supports differentiation. Cell Signal 2015;27 (09):1860-1872 
11 Kamal T, Green TN, Hearn JI, et al. $N$-methyl-d-aspartate receptor mediated calcium influx supports in vitro differentiation of normal mouse megakaryocytes but proliferation of leukemic cell lines. Res Pract Thromb Haemost 2017;02(01):125-138

12 Hitchcock IS, Skerry TM, Howard MR, Genever PG. NMDA receptor-mediated regulation of human megakaryocytopoiesis. Blood 2003;102(04):1254-1259

13 Ogura M, Morishima Y, Ohno R, et al. Establishment of a novel human megakaryoblastic leukemia cell line, MEG-01, with positive Philadelphia chromosome. Blood 1985;66(06): 1384-1392

14 Ogura M, Morishima Y, Okumura M, et al. Functional and morphological differentiation induction of a human megakaryoblastic leukemia cell line (MEG-01s) by phorbol diesters. Blood 1988; 72(01):49-60

15 Trécul A, Morceau F, Gaigneaux A, Schnekenburger M, Dicato M, Diederich M. Valproic acid regulates erythro-megakaryocytic differentiation through the modulation of transcription factors and microRNA regulatory micro-networks. Biochem Pharmacol 2014;92(02):299-311

16 Chen W, Arroyo JD, Timmons JC, Possemato R, Hahn WC. Cancer-associated PP2A Aalpha subunits induce functional haploinsufficiency and tumorigenicity. Cancer Res 2005;65(18): 8183-8192

17 Kalev-Zylinska ML, Hearn JI, Rong J, et al. Altered N-methyl Daspartate receptor subunit expression causes changes to the circadian clock and cell phenotype in osteoarthritic chondrocytes. Osteoarthritis Cartilage 2018;26(11):1518-1530

18 Kalev-Zylinska ML, Green TN, Morel-Kopp MC, et al. N-methyl-Daspartate receptors amplify activation and aggregation of human platelets. Thromb Res 2014;133(05):837-847

19 Livak KJ, Schmittgen TD. Analysis of relative gene expression data using real-time quantitative PCR and the 2(-Delta Delta C(T)) Method. Methods 2001;25(04):402-408

20 van Galen P, Kreso A, Mbong N, et al. The unfolded protein response governs integrity of the haematopoietic stem-cell pool during stress. Nature 2014;510(7504):268-272

21 Lasham A, Herbert M, Coppieters 't Wallant N, et al. A rapid and sensitive method to detect siRNA-mediated mRNA cleavage in vivo using 5' RACE and a molecular beacon probe. Nucleic Acids Res 2010;38(03):e19

22 Singleton DC, Rouhi P, Zois CE, et al. Hypoxic regulation of RIOK3 is a major mechanism for cancer cell invasion and metastasis. Oncogene 2015;34(36):4713-4722

23 Irizarry RA, Hobbs B, Collin F, et al. Exploration, normalization, and summaries of high density oligonucleotide array probe level data. Biostatistics 2003;04(02):249-264

24 Ambrosio AL, Boyle JA, Di Pietro SM. Mechanism of platelet dense granule biogenesis: study of cargo transport and function of Rab32 and Rab38 in a model system. Blood 2012;120(19): 4072-4081

25 Pérez-Riesgo E, Gutiérrez LG, Ubierna D, et al. Transcriptomic analysis of calcium remodeling in colorectal cancer. Int J Mol Sci 2017;18(05):18

26 Ramanathan G, Mannhalter C. Increased expression of transient receptor potential canonical 6 (TRPC6) in differentiating human megakaryocytes. Cell Biol Int 2016;40(02):223-231

27 Kaestner L, Wang X, Hertz L, Bernhardt I. Voltage-activated ion channels in non-excitable cells-a viewpoint regarding their physiological justification. Front Physiol 2018;09:450

28 Zhao P, Xiao X, Kim AS, et al. c-Jun inhibits thapsigargin-induced ER stress through up-regulation of DSCR1/Adapt78. Exp Biol Med (Maywood) 2008;233(10):1289-1300
29 Isakari Y, Sogo S, Ishida T, et al. Gene expression analysis during platelet-like particle production in phorbol myristate acetatetreated MEG-01 cells. Biol Pharm Bull 2009;32(03):354-358

30 Brignall R, Cauchy P, Bevington SL, et al. Integration of kinase and calcium signaling at the level of chromatin underlies inducible gene activation in T cells. J Immunol 2017;199(08):2652-2667

31 Kinney MA, Vo LT, Frame JM, et al. A systems biology pipeline identifies regulatory networks for stem cell engineering. Nat Biotechnol 2019;37(07):810-818

32 Zhu F, Feng M, Sinha R, Seita J, Mori Y, Weissman IL. Screening for genes that regulate the differentiation of human megakaryocytic lineage cells. Proc Natl Acad Sci U S A 2018;115(40):E9308-E9316

33 Kuvardina ON, Herglotz J, Kolodziej S, et al. RUNX1 represses the erythroid gene expression program during megakaryocytic differentiation. Blood 2015;125(23):3570-3579

34 Frontelo P, Manwani D, Galdass M, et al. Novel role for EKLF in megakaryocyte lineage commitment. Blood 2007;110(12): 3871-3880

35 Cohen S, Greenberg ME. Communication between the synapse and the nucleus in neuronal development, plasticity, and disease. Annu Rev Cell Dev Biol 2008;24:183-209

36 Albarrán L, Lopez JJ, Dionisio N, Smani T, Salido GM, Rosado JA. Transient receptor potential ankyrin-1 (TRPA1) modulates storeoperated $\mathrm{Ca}(2+)$ entry by regulation of STIM1-Orai1 association. Biochim Biophys Acta 2013;1833(12):3025-3034

37 Chen JL, Ping YH, Tseng MJ, et al. Notch1-promoted TRPA1 expression in erythroleukemic cells suppresses erythroid but enhances megakaryocyte differentiation. Sci Rep 2017;07:42883

38 Kobuke K, Oki K, Gomez-Sanchez CE, et al. Calneuron 1 increased $\mathrm{Ca}(2+)$ in the endoplasmic reticulum and aldosterone production in aldosterone-producing adenoma. Hypertension 2018;71(01): 125-133

39 Kim HJ, Soyombo AA, Tjon-Kon-Sang S, So I, Muallem S. The Ca $(2+)$ channel TRPML3 regulates membrane trafficking and autophagy. Traffic 2009;10(08):1157-1167

40 Pandey V, Chuang CC, Lewis AM, et al. Recruitment of NAADPsensitive acidic Ca2 + stores by glutamate. Biochem J 2009;422 (03):503-512

41 Kook SY, Jeong H, Kang MJ, et al. Crucial role of calbindin-D28k in the pathogenesis of Alzheimer's disease mouse model. Cell Death Differ 2014;21(10):1575-1587

42 Bellido T, Huening M, Raval-Pandya M, Manolagas SC, Christakos S. Calbindin-D28k is expressed in osteoblastic cells and suppresses their apoptosis by inhibiting caspase-3 activity. J Biol Chem 2000;275(34):26328-26332

43 Zunino R, Li Q Rosé SD, et al. Expression of scinderin in megakaryoblastic leukemia cells induces differentiation, maturation, and apoptosis with release of plateletlike particles and inhibits proliferation and tumorigenesis. Blood 2001;98(07):2210-2219

44 Polasek J. Platelet secretory granules or secretory lysosomes? Platelets 2005;16(08):500-501

45 Ambrosio AL, Di Pietro SM. Storage pool diseases illuminate platelet dense granule biogenesis. Platelets 2017;28(02):138-146

46 Ambrosio AL, Boyle JA, Di Pietro SM. TPC2 mediates new mechanisms of platelet dense granule membrane dynamics through regulation of Ca2 + release. Mol Biol Cell 2015;26(18):3263-3274

47 Shivarov V, Ivanova M, Tiu RV. Mutated calreticulin retains structurally disordered $\mathrm{C}$ terminus that cannot bind $\mathrm{Ca}(2+)$ : some mechanistic and therapeutic implications. Blood Cancer J 2014;04:e185

48 Nam AS, Kim KT, Chaligne R, et al. Somatic mutations and cell identity linked by Genotyping of Transcriptomes. Nature 2019; 571(7765):355-360 